\title{
Improvement and Sensitivity Analysis of Thermal Thin-Ice Thickness Retrievals
}

\author{
Susanne Adams, Sascha Willmes, David Schröder, Günther Heinemann, Martin Bauer, and Thomas Krumpen
}

\begin{abstract}
Considering the sea ice decline in the Arctic during the last decades, polynyas are of high research interest since these features are core areas of new ice formation. The determination of ice formation requires accurate retrieval of polynya area and thin-ice thickness (TIT) distribution within the polynya. We use an established energy balance model to derive TITs with MODIS ice surface temperatures $\left(T_{s}\right)$ and NCEP/DOE Reanalysis II in the Laptev Sea for two winter seasons. Improvements of the algorithm mainly concern the implementation of an iterative approach to calculate the atmospheric flux components taking the atmospheric stratification into account. Furthermore, a sensitivity study is performed to analyze the errors of the ice thickness. The results are the following: 1) 2-m air temperatures $\left(T_{a}\right)$ and $T_{s}$ have the highest impact on the retrieved ice thickness; 2 ) an overestimation of $T_{a}$ yields smaller ice thickness errors as an underestimation of $\left.T_{a} ; 3\right)$ NCEP $T_{a}$ shows often a warm bias; and 4) the mean absolute error for ice thicknesses up to $20 \mathrm{~cm}$ is $\pm 4.7 \mathrm{~cm}$. Based on these results, we conclude that, despite the shortcomings of the NCEP data (coarse spatial resolution and no polynyas), this data set is appropriate in combination with MODIS $T_{s}$ for the retrieval of TITs up to $20 \mathrm{~cm}$ in the Laptev Sea region. The TIT algorithm can be applied to other polynya regions and to past and future time periods. Our TIT product is a valuable data set for verification of other model and remote sensing ice thickness data.
\end{abstract}

Index Terms-Laptev Sea, MODIS, remote sensing, thin-ice thickness.

\section{INTRODUCTION}

W IND-driven polynyas are meso- to small-scale areas of open water and/or thin ice occurring in Arctic and Antarctic shelf seas. Regarding the trend of shrinking sea ice extent and thickness in the Arctic during the last decades [1], [2], polynyas are of high research interest since these features are core areas of new ice formation. The calculation of ice production requires precise knowledge about the fraction of open water and the thickness distribution of thin sea ice within polynyas [3], [4]. The largest ice formation rates are found in open-water regions. Thin ice acts as an insulating layer between

Manuscript received March 18, 2012; revised August 15, 2012; accepted August 30, 2012. This work was supported by the German Ministry for Education and Research Laptev Sea System project (Grants 03G0639A and 0360639E).

S. Adams, S. Willmes, G. Heinemann, and M. Bauer are with the Department of Environmental Meteorology, Faculty of Geography/Geosciences, University of Trier, Trier 54296, Germany.

D. Schröder is with the Centre for Polar Observation and Modelling, University College London, London WC1E 6BT, U.K.

T. Krumpen is with the Climate Sciences/Sea Ice Physics, Alfred-Wegener Institute for Polar and Marine Research, Bremerhaven 27515, Germany.

Color versions of one or more of the figures in this paper are available online at http://ieeexplore.ieee.org.

Digital Object Identifier 10.1109/TGRS.2012.2219539 ocean and atmosphere. Reference [5] suggests that a thin-ice layer of around $5 \mathrm{~cm}$ reduces the turbulent heat fluxes by up to $270 \mathrm{Wm}^{-2}$ depending on the temperature conditions and wind speed of the atmospheric boundary layer above the thin ice. Thus, thin-ice thickness (TIT) is a key variable when ice production is derived. In terms of that, a detailed investigation of the uncertainties in the variables required for the TIT retrieval is necessary to determine the accuracy of the ice thickness distribution within the polynya.

Our regional focus is on the Laptev Sea of the Siberian Arctic [located between $100^{\circ} \mathrm{E}$ to $140^{\circ} \mathrm{E}$ and $70^{\circ} \mathrm{N}$ to $80^{\circ} \mathrm{N}$; Fig. 1(a)], which is an area of high new ice formation rates examined in a various number of studies (e.g., [3], [4], and [6]-[8]). These and other studies show that accurate data sets for the polynya area and ice thickness distribution within the polynya are needed. Remote sensing data yield the potential to retrieve these two variables over large areas and long time periods.

Polynya area and thin-ice distribution can be derived from passive microwave data. Several sea ice concentration (SIC) products are calculated from the Special Sensor Microwave Imager (SSM/I) brightness temperatures for the last 30 years with a spatial resolution of $25 \times 25 \mathrm{~km}^{2}$ [9]-[11] and from the Advanced Microwave Scanning Radiometer-Earth Observing System (AMSR-E) brightness temperatures for the last 10 years with a spatial resolution of $6.25 \times 6.25 \mathrm{~km}^{2}$ [12]. Based on SICs, the polynya area can be estimated using a threshold method (e.g. [13]-[15]). Another possibility in classifying the polynya area is by using the Polynya Signature Simulation Method (PSSM) based on SSM/I (AMSR-E) brightness temperatures [3], [16]-[19]. The PSSM method depends on polarization ratios of the 37.5 (36) and 85 (89) $\mathrm{GHz}$ frequencies utilizing the high resolution of the 85 (89) $\mathrm{GHz}$ channel and the less atmospheric disturbed 37.5 (36) GHz channel. TITs of up to $20 \mathrm{~cm}$ are determined using these polarization ratios of SSM/I and AMSR-E brightness temperatures and a regression model based on thermal TITs derived from optical remote sensing data (see the following discussion and [19]-[23]). Due to the coarse spatial resolution of these passive microwave data sets, small flaw polynyas are often not resolved. An advantage of these data sets is the complete daily coverage.

Another option to attain TIT and polynya area is by using thermal infrared data. The method is based on the strong relation between ice surface temperatures and TITs. Ice thicknesses are calculated using ice surface temperatures and additional atmospheric data, with the condition that the total atmospheric energy flux is balanced by the conductive heat flux through the ice. The calculation of thermal TITs started more than 30 years ago using airborne infrared imagery in combination with a very 
(a)
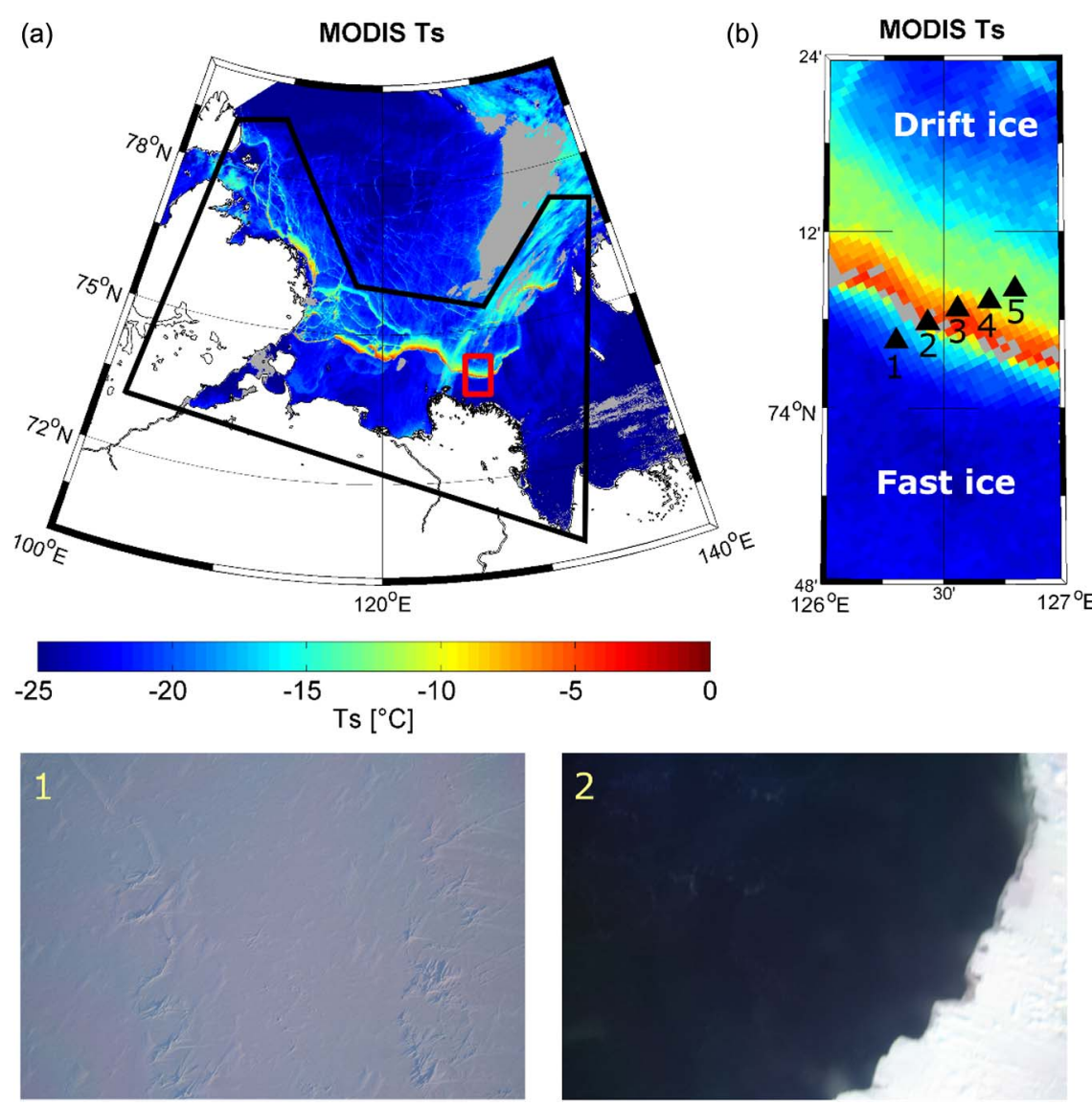
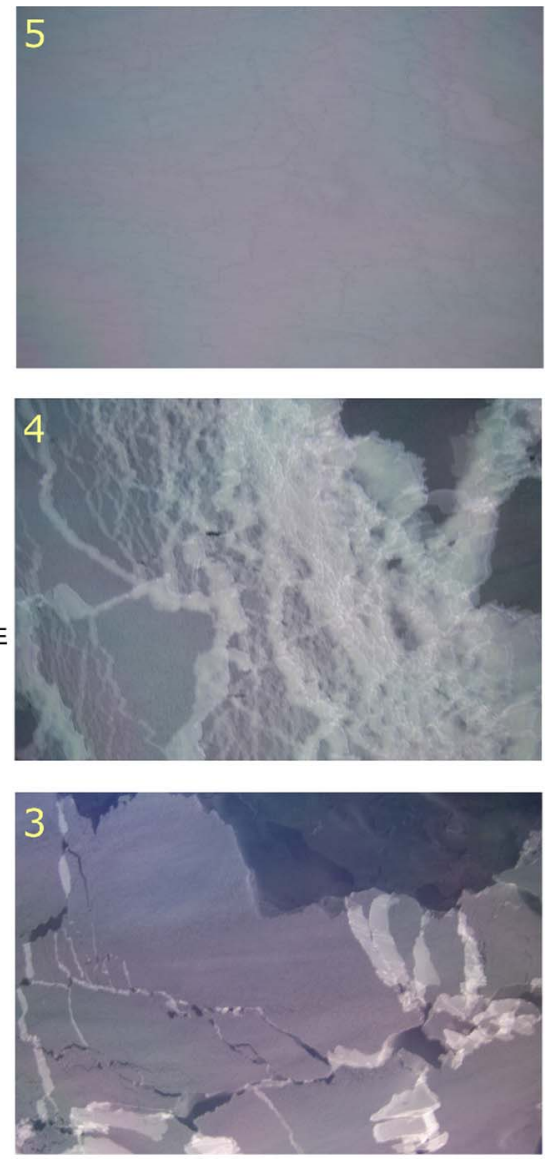

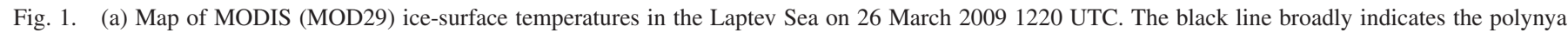

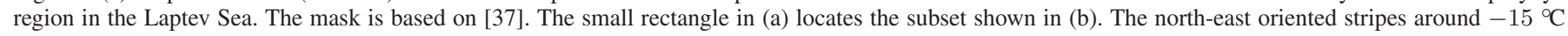

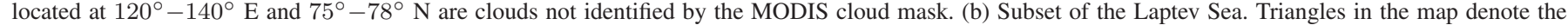

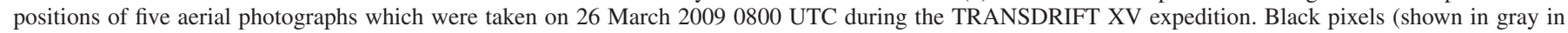
color version of this figure) in map (a) and (b) mark data gaps due to clouds.

simple surface energy model [24]. Since the 1980s, satellite thermal infrared data are provided by the Advanced Very High Resolution Radiometer (AVHRR) with a spatial resolution of $\sim 1 \times 1 \mathrm{~km}^{2}$. A first thin-ice retrieval study using AVHRR is accomplished by [25]. They applied the method in [24] as well as a simple theoretical approach [26] and found that AVHRR surface temperatures are reliable, but the retrieved ice thickness results are ambiguous, which might arise from simplified parameterizations of the fluxes or inappropriate atmospheric data. Improvement of the thin-ice retrieval is continued by [27]. They used AVHRR data in a thermodynamic ice growth model [28] to retrieve the ice thicknesses up to $50 \mathrm{~cm}$ with a relative error of $\pm 20 \%$. Compared to the previous algorithms, this model is more detailed concerning the calculation of the net total radiation balance, the separate treatment of the turbulent heat fluxes, and the conductivity of the ice/snow layer. Based on the method in [27], [19] and [29]-[31] performed case studies with a slightly modified algorithm for Arctic shelf seas. Error analyses of the ice thickness case studies show a high quality of this data set in comparison to other thin-ice data sets (e.g., about $80 \%$ agreement for moored or submarine ULS; [30], [32]).

What we apply in the present study is a surface-energy balance model (Fig. 2) based on the TIT retrieval of [31] us- ing Moderate Resolution Imaging Spectroradiometer (MODIS) thermal infrared imagery. The main advantage of MODIS compared to AVHRR is the improved cloud detection. The parameterizations of surface-energy fluxes in previous TIT retrieval methods are often not the state of the art from the view of an atmospheric boundary researcher, and therefore, more improvements are needed. The aims of the study are the following:

1) to improve the TIT algorithm by including better parameterizations;

2) to perform a thorough sensitivity analysis of the TIT algorithm and to quantify the errors;

3) to produce a MODIS thin-ice thickness product for two winter seasons for the Laptev Sea.

This paper is structured as follows. After an introduction of the data sets in Section II, the TIT algorithm is described. The results concerning the improvement of the algorithm are discussed in Section III. Section IV deals with the statistical and comparative sensitivity analysis. A summary and the overall conclusion of the publication together with an outlook are given in Section V. 
This article has been accepted for inclusion in a future issue of this journal. Content is final as presented, with the exception of pagination.

TABLE I

SPECIFICATIONS OF THE ATMOSPHERIC DATA SETS NCEP AND COSMO

\begin{tabular}{c|c|c}
\hline Model & NCEP & COSMO \\
\hline Spatial resolution & $1.75^{\circ}(\sim 200 \mathrm{~km})$ Global & $5 \mathrm{~km} \mathrm{Laptev} \mathrm{Sea}$ \\
\hline Temporal resolution & $6 \mathrm{~h}$ & $1 \mathrm{~h}$ \\
\hline Availability since 2000* & $2000-2012$ & Case studies \\
\hline Variables & $\begin{array}{c}\text { 2-m air temperature, 10-m wind speed, 2-m specific } \\
\text { humidity, mean sea level pressure }\end{array}$ & $\begin{array}{c}\text { 2-m air temperature, 10-m wind speed, 10-m specific humidity, } \\
\text { mean sea level pressure }\end{array}$ \\
\hline $\begin{array}{c}\text { Quality of data in terms } \\
\text { of polynyas }\end{array}$ & $\begin{array}{c}\text { Polynyas not captured resulting in too cold 2-m air } \\
\text { temperatures above polynyas, warm bias in 2-m air } \\
\text { temperature }\end{array}$ & $\begin{array}{c}\text { Polynyas captured by using AMSR-E sea-ice fields (sea-ice } \\
\text { concentration }<70 \% \text { equals to polynya area in model setup); } \\
\text { composed data set of daily model runs }\end{array}$ \\
\hline $\begin{array}{c}\text { Impact on retrieved } \\
\text { ice thickness }\end{array}$ & $\begin{array}{c}\text { Due to the frequently occurring warm air temperature } \\
\text { bias ice thickness could be overestimated, otherwise air } \\
\text { temperatures are underestimated resulting in } \\
\text { underestimated ice thicknesses }\end{array}$ & $\begin{array}{c}\text { Highest accuracy if MODIS and AMSR-E give a similar polynya } \\
\text { signal, otherwise underestimation of air temperature resulting in } \\
\text { an underestimation of the ice thickness }\end{array}$ \\
\hline
\end{tabular}

*MODIS ice-surface temperatures available since 2000.

\section{DATA SETS}

\section{A. Remote Sensing Data Sets}

MODIS Ice Surface Temperatures: The TIT algorithm used is based on MODIS ice surface temperatures $\left(T_{s}\right)$. We use the MODIS Terra and Aqua Sea Ice Extent product (MOD/MYD29; [33]) that includes ice surface temperatures for the winters 2007/2008 and 2008/2009. The data are provided with a spatial resolution of $1 \times 1 \mathrm{~km}^{2}$ and an accuracy of $\pm 1.6{ }^{\circ} \mathrm{C}$ [34]. The data product is available through the US National Aeronautics and Space Administration (NASA) Warehouse Inventory Search Tool Web site (https://wist.echo.nasa. gov). The quality-proofed MODIS cloud mask (MOD/MYD35) is implemented to this MODIS $T_{s}$ product to exclude cloudy regions [34]-[36]. The cloud mask algorithm has difficulties in identifying sea smoke and thin low clouds resulting in too high ice surface temperatures where these clouds occur [Fig. 1(a)].

A polynya mask is applied according to [37] to MODIS $T_{s}$ to focus our study on the polynya regions in the Laptev Sea [Fig. 1(a)].

We use the TIT algorithm only for nighttime MODIS $T_{s}$ pixels. For an accurate calculation of the short-wave radiation balance, the variables albedo, solar incident radiation, and bidirectional reflectance would have to be taken into account [38]. Currently, the parameterization of these variables is difficult due to the lack of adequate data of incident solar radiation and albedo with sufficient spatial and temporal resolutions. A pixelby-pixel calculation of sunrise and sunset is implemented to exclude regions affected by possible incident solar radiation.

AMSR-E SICs: We obtain the AMSR-E SICs with a spatial resolution of $6.25 \times 6.25 \mathrm{~km}^{2}$ for the winters $2007 / 2008$ and 2008/2009 from the University of Hamburg [11], [12]. AMSR-E SICs are used to calculate polynya area (POLA) for comparison with MODIS TIT results because SICs are set as initial sea ice conditions in the consortium for small-scale modeling (COSMO) model configuration (see the following discussion and [39]).

\section{B. Model Data Sets for Atmospheric Data}

Besides MODIS $T_{s}$, atmospheric variables are required for the calculation of TITs. Each of the atmospheric variables is taken from two atmospheric models to retrieve two TIT products which can be compared with each other.

NCEP: We use US National Centers for Environmental Prediction (NCEP)/Department of Energy (DOE) Reanalysis II [40]. In the following, the data set is referred to as NCEP. The global data set has a spatial resolution of $1.75^{\circ}(\sim 200-\mathrm{km}$ grid size in our area) and a temporal resolution of $6 \mathrm{~h}$ (Table I). The variables 2-m air temperature $\left(T_{a}\right), 10-\mathrm{m}$ wind speed $\left(U_{10 m}\right), 2-m$ specific humidity $\left(q_{a}\right)$, mean sea level pressure $(p)$ are used.

COSMO: COSMO is a nonhydrostatic regional weather prediction model [41], [42]. Since 1999, COSMO has been the main part of the German Weather Service's numerical weather forecast system. Reference [39] used the model for the Laptev Sea region and implemented a thermodynamic sea ice model in COSMO. A high-resolution version of COSMO is nested with two steps in the Global Model Extended (GME with 40-km spatial resolution). AMSR-E SIC is included in the model setup as an initial field of sea ice conditions. With daily updated AMSR-E SIC, model runs of $30 \mathrm{~h}$ (6-h spin-up time inclusive) were completed and composed to one data set. The simulations have a horizontal resolution of $5 \mathrm{~km}$ and a temporal resolution of $1 \mathrm{~h}$ (Table I). COSMO simulations are abbreviated as COSMO in the following.

\section{RETRIEVAL OF TITs}

\section{A. TIT Algorithm}

The strong relation between ice surface temperatures and TITs is shown in Fig. 1. The comparison of the ice surface temperatures and the aerial photographs show that, in contrast to the cold fast ice, open water has a temperature near its freezing point. Going further offshore, the temperature decreases with increasing ice thickness.

Our thin-ice retrieval is based on the model of [31]. We modified the algorithm at the following two calculation steps:

1) calculation of the turbulent heat fluxes by an iterative stability dependent bulk approach;

2) improved parameterization of the calculation of the atmospheric emission coefficient required for the determination of the incoming long-wave radiation. 


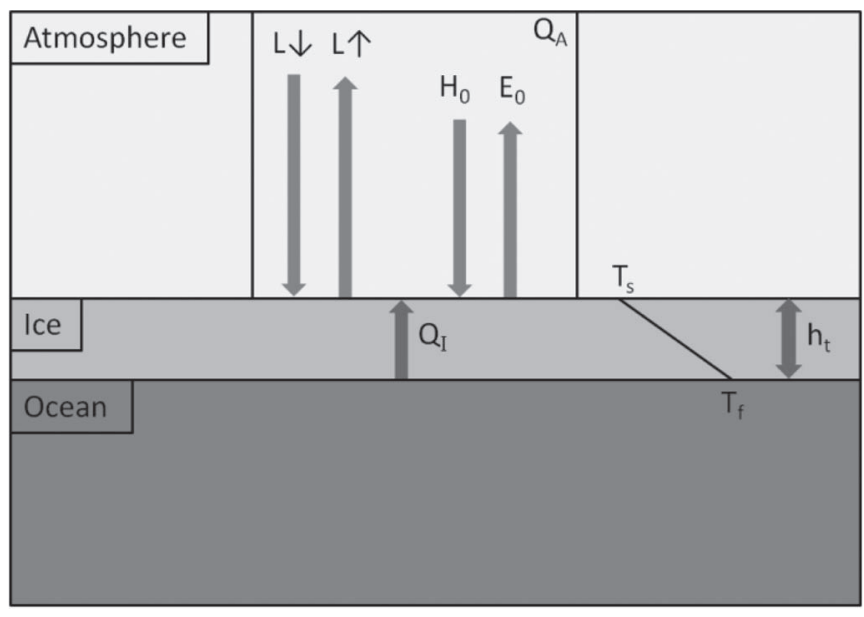

Fig. 2. TIT retrieval scheme. $L \downarrow$ and $L \uparrow$ are the incoming and outgoing long-wave radiation components, $H_{0}$ and $E_{0}$ are the turbulent heat fluxes, $Q_{A}$ is the net energy flux to the atmosphere, $Q_{I}$ is the conductive heat flux through the ice, $T_{s}$ is the ice surface temperature, $T_{f}$ is the freezing temperature of sea water, and $h_{t}$ is the ice thickness.

The energy balance model in Fig. 2 is described in more detail in the following. The algorithm is based on the condition that the total energy flux to the atmosphere $Q_{A}(1)$ is equal to the conductive heat flux through the ice $Q_{I}$.

$Q_{A}$ is calculated as follows:

$$
Q_{A}=Q_{0}-H_{0}-E_{0}
$$

where $Q_{0}$ is the net radiation balance, $H_{0}$ is the sensible heat flux, and $E_{0}$ is the latent heat flux. Ice production will occur if the energy flux to the atmosphere $Q_{A}$ is negative and the water is at its freezing point. The latter is generally observed throughout the winter period.

As mentioned previously, we exclude daytime conditions [32]. Therefore, $Q_{0}$ is determined by the long-wave radiation components only

$$
Q_{0}=L \downarrow-L \uparrow .
$$

The incoming long-wave radiation $L \downarrow$ is calculated using Stefan-Boltzmann's law

$$
L \downarrow=\varepsilon_{a} \sigma T_{a}^{4}
$$

where $T_{a}$ is the 2-m air temperature, $\sigma$ is the Stefan-Boltzmann constant, and $\varepsilon_{a}$ is the atmospheric emission coefficient parameterized according to [43]

$$
\begin{aligned}
& \varepsilon_{a}=\left(0.0003\left(T_{a}[K]-273.16\right)^{2}-0.0079\right. \\
& \left.\times\left(T_{a}[K]-273.16\right)+1.2983\right) *\left(e_{a}[h P a] / T_{a}[K]\right)^{1 / 7}
\end{aligned}
$$

with $e_{a}$ as the 2-m water-vapor pressure which is calculated using the specific humidity $q_{a}$ and the mean sea-level pressure $p$

$$
e_{a}=\left(q_{a} p\right) / 0.622
$$

The outgoing long-wave radiation $L \uparrow$ is calculated using the ice surface temperature $T_{s}$ and the emission coefficient of the surface $\varepsilon_{s}$ taken as 1 [44]

$$
L \uparrow=\varepsilon_{s} \sigma T_{s}^{4} .
$$

The latent heat flux $E_{0}$ and the sensible heat flux $H_{0}$ are calculated using an iterative bulk approach following [45]. This approach includes the atmospheric stability using the Monin-Obukhov similarity theory and the associated universal functions (see Section III-B). The 10-m wind speed is interpolated to the 2-m level. A constant roughness length for momentum $z_{0}$ of $1 \times 10^{-3} \mathrm{~m}$ is used.

For the calculation of the conductive heat flux through the ice $Q_{I}$, we assume a pure ice layer with a linear temperature profile [30], [32]. As in other comparable studies (e.g., [30]), we neglect snow on the thin ice, which is in accordance with in situ observations during the TRANSDRIFT XV expedition (see Fig. 1). The heat flux through the thin-ice layer $Q_{I}$ can then be calculated as follows:

$$
Q_{I}=k_{i}\left(T_{s}-T_{f}\right) / h_{t}
$$

where $k_{i}$ is the conductivity of pure ice $\left(2.03 \mathrm{~W} \mathrm{~K}^{-1} \mathrm{~m}^{-1}\right)$, $T_{f}$ is the freezing temperature of sea water, and $h_{t}$ is the ice thickness.

As described previously, $Q_{A}$ is equal to $Q_{I}$, which allows us to solve (7) for the ice thickness $h_{t}$

$$
h_{t}=k_{i}\left(T_{s}-T_{f}\right) / Q_{A} .
$$

As input variables, we use MODIS $T_{s}$ as well as atmospheric variables to calculate the components of the energy flux to the atmosphere $Q_{A}$. Each atmospheric variable is taken from the two different data sets NCEP and COSMO. These data sets are reprojected to a $1 \times 1 \mathrm{~km}^{2}$ grid. The TIT products are derived using MODIS ice surface temperatures in combination with the following:

1) NCEP atmospheric variables, referred to as TIT $_{\text {MODIS+NCEP }}$

2) COSMO atmospheric variables, referred to as TIT $_{\text {MODIS+COSMO }}$.

We calculate TITs for the two winter seasons 2007/2008 and 2008/2009 with MODIS $T_{s}$ and NCEP atmospheric variables. TITs with MODIS $T_{s}$ and COSMO atmospheric variables are calculated for case studies to compare both products with each other.

\section{B. Improvement of the Atmospheric Flux Calculations}

In this section, the modifications of the thin-ice algorithm are analyzed and discussed in comparison to [31]. We regard TITs up to $50 \mathrm{~cm}$.

The most significant modification of the TIT algorithm concerns the calculation of the turbulent heat fluxes. Reference [31] approximated the 2-m wind speed using the geostrophic wind and a reduction factor of 0.34 [46]. Bulk equations with a constant transfer coefficient for heat $\left(C_{H}\right)$ of $3 \times 10^{-3}$ for very 


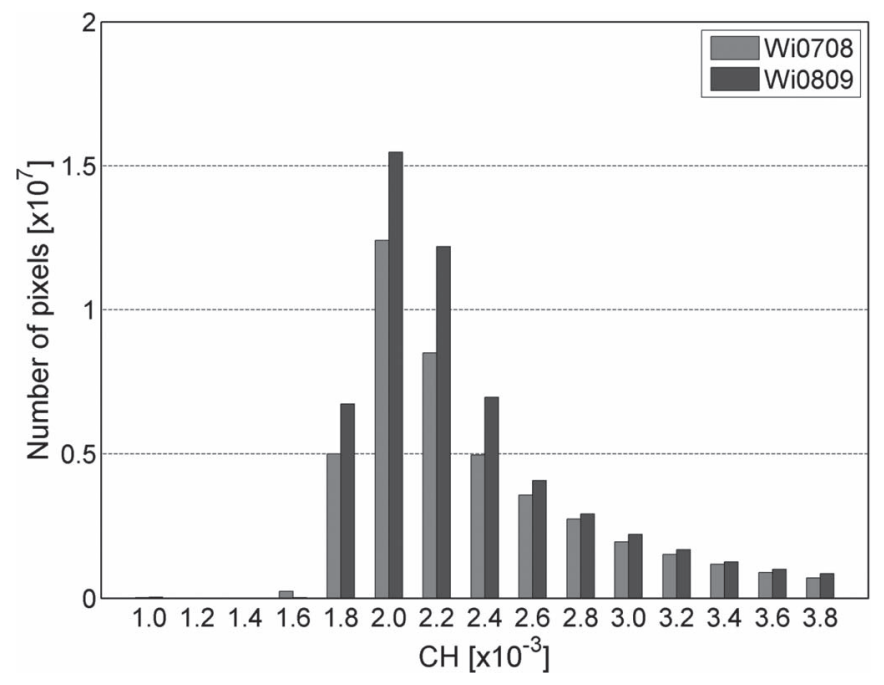

Fig. 3. Frequency distribution of the heat transfer coefficient $\left(C_{H}\right)(0.2 \times$ $10^{-3}$ bins) for the winters 2007/2008 (light gray) and 2008/2009 (dark gray). The calculation of $C_{H}$ is based on MODIS ice surface temperatures and NCEP atmospheric variables. The influence of the atmospheric stratification to $C_{H}$ is shown.

thin ice and $1.75 \times 10^{-3}$ for thicker ice are used (thresholds for very thin ice and thicker ice are not specified in their paper). In contrast, we apply an iterative approach following [45] to calculate the turbulent heat fluxes, which takes into account the near-surface atmospheric stratification for $C_{H}$. The wind speed is taken from atmospheric model data and is adjusted to a height of $2 \mathrm{~m}$ using a constant roughness length of $1 \times 10^{-3} \mathrm{~m}$.

Fig. 3 shows a histogram of $C_{H}$ calculated with NCEP data for the two winter seasons 2007/2008 and 2008/2009 for all pixels with an ice thickness between 0 and $50 \mathrm{~cm}$. The maximum frequency of $C_{H}$ is at $2.0 \times 10^{-3}$ for both winter seasons. However, also larger values of up to $3.8 \times 10^{-3}$ occur for very unstable stratification.

The constant values for $C_{H}$ of $1.75 \times 10^{-3}$ and $3.0 \times 10^{-3}$ used by [31] seem to be reasonable compared to our results (using a variable $C_{H}$ ). In order to quantify the effect of these constant transfer coefficients on the ice thickness retrieval, we select ten MODIS scenes for polynya events listed in Table II. If a constant $C_{H}$ of $3 \times 10^{-3}$ is used instead of a variable coefficient, the ice thickness between 0 and $50 \mathrm{~cm}$ will be, on average, $1.9 \mathrm{~cm}$ thinner (Table III). A maximum of 4-cm difference occurs for the 10-20-cm ice class. Using a constant $C_{H}$ of $1.75 \times 10^{-3}$, the ice thickness is, on average, $6.9 \mathrm{~cm}$ thinner in comparison to the iterative approach (Table III). Ice thicknesses calculated with both constant heat transfer coefficients are, in general, underestimated. For the ten MODIS scenes, we can conclude that, for simplification, a $C_{H}$ of $3.0 \times 10^{-3}$ is applicable for ice thicknesses up to $50 \mathrm{~cm}$. A constant $C_{H}$ of $1.75 \times 10^{-3}$ yields larger ice thickness differences for all ice classes compared to a variable $C_{H}$.

This examination implies that $C_{H}$ values used in the study in [31] are suitable as a first approach. However, the iterative approach following [45] as used in our model takes the atmospheric stratification into account and determines pixelwise $C_{H}$, improving the accuracy of the coefficient and thus the accuracy of the derived TITs.
TABLE II

TEN MODIS SCEnES EQUALly Distributed Over THE Two Winter SEASONS 2007/2008 AND 2008/2009. EACH ScENE Shows A Distinctive Polynya EVEnt. The Scenes ARe Used Instead of All for SOME ANALYSES

\begin{tabular}{lcc}
\hline \multicolumn{3}{c}{ 10 MODIS scenes for analysis purposes } \\
\hline Satellite & Date & Time (UTC) \\
\hline Terra & 31 December 2007 & 0520 \\
\hline Terra & 27 January 2008 & 1310 \\
\hline Terra & 28 February 2008 & 1310 \\
\hline Terra & 16 April 2008 & 1310 \\
\hline Terra & 23 February 2009 & 1125 \\
\hline Terra & 18 March 2009 & 0955 \\
\hline Aqua & 4 January 2008 & 0200 \\
\hline Aqua & 28 December 2008 & 2025 \\
\hline Aqua & 31 January 2009 & 0335 \\
\hline Aqua & 18 April 2009 & 1805 \\
\hline
\end{tabular}

TABLE III

Comparison of tit Calculated With a Constant Heat Transfer COEFFICIENT $\left(1.75 \times 10^{-3}\right.$ AND $\left.3.0 \times 10^{-3}\right)$ AND A VARIABLE HEAT TRANSFER COEFFicient USING THE TEN EXamples SHOWN IN TABle II. ABSOLUTE DifFERENCES BETWEEN THE ICE THICKNESSES For DifFerent ICE Classes ARe Shown

\begin{tabular}{c|c|c}
\hline TIT classes & $\begin{array}{c}\text { difference } \mathbf{C}_{\mathbf{H}} \mathbf{1 . 7 5} \times \mathbf{1 0}^{\mathbf{- 3}}- \\
\text { variable } \mathbf{C}_{\mathbf{H}}(\mathbf{c m})\end{array}$ & $\begin{array}{c}\text { difference } \mathbf{C}_{\mathbf{H}} \mathbf{3 . 0 \times 1 0 ^ { - \mathbf { 3 } } -} \\
\text { variable } \mathbf{C}_{\mathbf{H}}(\mathbf{c m})\end{array}$ \\
\hline $\mathbf{0} \mathbf{- 1 0} \mathbf{~ c m}$ & -3.9 & -0.7 \\
\hline $\mathbf{1 0} \mathbf{2 0} \mathbf{~ c m}$ & -9.2 & -4.0 \\
\hline $\mathbf{2 0} \mathbf{- 3 0} \mathbf{~ c m}$ & -9.9 & -3.1 \\
\hline $\mathbf{3 0} \mathbf{- 4 0} \mathbf{~ c m}$ & -8.2 & -1.3 \\
\hline $\mathbf{4 0} \mathbf{- 5 0} \mathbf{~ c m}$ & -3.5 & -0.7 \\
\hline mean & -6.9 & -1.9 \\
\hline
\end{tabular}

A second modification concerns the parameterization scheme of the atmospheric emission coefficient. Reference [31] applied the parameterization of the atmospheric emission coefficient following [47] (EF61). In our study, we determine the atmospheric emission coefficient using a newer improved approach following [43] (JI06). The main difference between the two approaches is that EF61 parameterizes the emissivity using the water vapor pressure only and JI06 uses additionally the 2-m air temperature. JI06 improved the parameterization scheme of [48] for clear-sky polar regions using data of two field campaigns in the Canadian Arctic. The developed empirical model is compared with 11 other parameterization schemes including EF61. JI06's results indicate that their method has the smallest mean error and that their method is transferrable to other cold regions.

The calculation of the atmospheric emission coefficient with MODIS $T_{s}$ and NCEP atmospheric variables using JI06's method for winter season 2007/2008 gives coefficients between 0.59 and 0.82 . Using EF61's method, the coefficient varies between 0.75 and 0.78 , covering a smaller range. Ice thicknesses are retrieved for the ten MODIS scenes (Table II) using JI06's and EF61's parameterizations. A comparison of the ice thickness distributions shows that JI06's parameterization, in general, results in thinner ice. The ice thickness is up to $7 \mathrm{~cm}$ thinner than when using EF61's parameterization scheme. In a 
TABLE IV

UNCERTAINTIES OF THE INPUT VARIABLES USED FOR THE CALCULATION of TIT. UnCERTAinties ARE BASED on the MENTIONED REFERENCES

\begin{tabular}{l|c|c}
\hline & MODIS & NCEP \\
\hline $\begin{array}{l}\text { Ice-surface } \\
\text { temperature }\left({ }^{\circ} \mathrm{C}\right)\end{array}$ & \pm 1.6 & \\
\hline $\begin{array}{l}\text { 2-m air temperature } \\
([334])\end{array}$ & & \pm 4.5 \\
\hline $10-\mathrm{C})$ & & $([15],[49])$ \\
$(\mathrm{m} / \mathrm{s})$ & \pm 1.3 \\
Relative humidity & & $([15],[49])$ \\
$(\%)$ & & \pm 20 \\
\hline
\end{tabular}

few cases, the ice is thicker using JI06's parameterization, with a maximum of $1 \mathrm{~cm}$.

Assuming that JI06's approach gives more accurate results than EF61's approach, the ice thicknesses in previous studies are mostly slightly overestimated (means of ten MODIS scenes between -1.1 and $+2.6 \mathrm{~cm})$.

\section{Sensitivity Analysis}

\section{A. Statistical Sensitivity Analysis}

1) Methods: As a first step, we analyze the importance of each individual input variable on the retrieved TIT in dependence to its uncertainty. The uncertainties of the input variables $T_{s}, T_{a}, U_{10 m}$, and relative humidity $\mathrm{RH}$ are deduced on the basis of verification studies (Table IV). We assume the following uncertainties based on [15], [34], and [49]: $\Delta T_{s}= \pm 1.6{ }^{\circ} \mathrm{C}$, $\Delta T_{a}= \pm 4.5^{\circ} \mathrm{C}, \Delta U_{10 m}= \pm 1.3 \mathrm{~m} \mathrm{~s}^{-1}$, and $\Delta \mathrm{RH}= \pm 20 \%$. We use the relative humidity instead of the specific humidity to avoid inconsistencies between air temperature and saturation humidity. The analysis is performed using the MODIS scenes of Table II. TIT fields are calculated, varying the input variables sequentially with their minimum and maximum uncertainties.

As a second step, we perform a Monte Carlo error estimation for the MODIS TITs to account for the combination of the uncertainties of the input variables and their impact on the retrieved ice thicknesses. The Monte Carlo error estimation is performed for the input variables MODIS $T_{s}$ and NCEP atmospheric variables. MODIS scenes of winter 2007/2008 (2401) and MODIS scenes of winter 2008/2009 (2240) are used. The thin-ice retrieval is a nonlinear function of the input variables

$$
h_{t}=h_{t}\left(T_{s}, T_{a}, U_{10 m}, R H\right) .
$$

For each MODIS scene, 100 random values within the error range of each variable (Table IV) are generated. Then, a population of 100 synthetic thin-ice distributions is calculated using MODIS and NCEP input variables plus a random error value. Since the focus is on the ice production, only combinations with a negative net energy flux to the atmosphere $Q_{A}$ and unstable stratification are used (see Section III-A). Due to these restrictions, the number of TIT calculations can be less than 100 for some MODIS pixels (89 on average).

2) Results and Discussion: The first part of the statistical analysis gives insight into the ranking of the input variables in terms of their impact on the retrieved ice thickness. The analysis focuses on ice thicknesses up to $20 \mathrm{~cm}$ for clarity. In the
TABLE V

RANKING OF THE INPUT VARIABLES IN TERMS OF THEIR IMPACT TO THE Retrieved Polynya Area (Thin ICE $<20 \mathrm{~cm}$ ). The Averaged POLYNYA AREA (POLA) OF TEN MODIS SCENES (TABLE II) AND THE ANOMALY IN PERCENT WHEN VARYING THE INPUT VARIABLES $\left(T_{s}=\right.$ MODIS ICE SURFACE TEMPERATURE, $T_{a}=2-\mathrm{m}$ air temperature, $\mathrm{RH}=$ relative humidity, AND $U_{10 m}=10$-m wind speed) ABOUT THEIR Minimum and Maximum Uncertainties ARe Shown (TABle IV). THE TIT IS CALCULATED With MODIS $T_{S}$ AND NCEP ATMOSPHERIC VARIABLES

\begin{tabular}{|c|c|c|c|c|c|}
\hline Variable & $\begin{array}{c}\text { TIT } \\
\text { POLA } \\
\left(\mathrm{km}^{2}\right)\end{array}$ & $\begin{array}{c}\mathrm{T}_{\mathrm{s}} \\
+1.6^{\circ} \mathrm{C}\end{array}$ & $\begin{array}{c}T_{s} \\
-1.6^{\circ} \mathrm{C}\end{array}$ & $\begin{array}{c}\mathrm{T}_{\mathrm{a}} \\
+4.5^{\circ} \mathrm{C}\end{array}$ & $\begin{array}{c}\mathrm{T}_{\mathrm{a}} \\
-4.5^{\circ} \mathrm{C}\end{array}$ \\
\hline average/change & 8,780 & $+75 \%$ & $-44 \%$ & $-55 \%$ & $+141 \%$ \\
\hline Variable & $\begin{array}{c}\text { RH } \\
+\mathbf{2 0} \%\end{array}$ & $\begin{array}{c}\text { RH } \\
-20 \%\end{array}$ & $\begin{array}{l}\mathrm{U}_{10 \mathrm{~m}} \\
+1.3 \\
\mathrm{~ms}^{-1} \\
\end{array}$ & $\begin{array}{c}\mathrm{U}_{10 \mathrm{~m}} \\
-1.3 \mathrm{~ms}^{-} \\
1\end{array}$ & \\
\hline average/change & $-8 \%$ & $+10 \%$ & $+22 \%$ & $-23 \%$ & \\
\hline
\end{tabular}

following, the results of the Monte Carlo error estimation show that a maximum limit of 20 -cm ice thickness is a better choice than $50 \mathrm{~cm}$. The errors in the ice thickness become very large when the ice is thicker than $20 \mathrm{~cm}$. Table $\mathrm{V}$ shows the reference POLA (including all thin-ice pixels up to $20 \mathrm{~cm}$ ) and the anomaly in percent when varying the input variables about their minimum and maximum uncertainties. The averaged reference POLA of the ten examples listed in Table II is $8780 \mathrm{~km}^{2}$. The results with varying uncertainties indicate that $T_{a}$ has the highest (change in POLA of $+141 /-55 \%$ ) and RH the lowest impact (change in POLA of $+10 /-8 \%$ ) on the derived TIT and, hence, POLA. $T_{s}$ has the second highest impact on the calculated ice thickness (change in POLA of $+75 /-44 \%$ ). The hierarchy is the following: $T_{a}, T_{s}, U_{10 m}$, and $\mathrm{RH}$.

After the examination of POLA, the impact of the input variables' uncertainties to different ice classes is investigated. Fig. 4(a) shows the average number of pixels of the reference ice thicknesses for the three ice classes $0-5 \mathrm{~cm}(\mathrm{cl1})$, 5-10 cm (cl2), and 10-20 cm (cl3). The other subplots of Fig. 4(b-i) present the anomaly to the reference ice thickness, varying each input variable about their minimum and maximum uncertainties. We find that the uncertainties in the retrieved ice thicknesses up to $5 \mathrm{~cm}$ are smallest for each variable (e.g., $+66 /-42 \%$ for $T_{s}$ ). Higher anomalies are found for the ice class $10-20 \mathrm{~cm}$ for all input variables, indicating an increase in ice thickness uncertainty with thicker ice (e.g., $+72 /-44 \%$ for $T_{s}$ ). The highest anomalies are found for $T_{a}$ : an underestimation of $T_{a}$ results in $+154 \%$ more, and an overestimation of $T_{a}$ results in $-57 \%$ less thin-ice pixels between 10 and $20 \mathrm{~cm}$. This is in agreement with the analysis of POLA where the overestimation of POLA is highest when $T_{a}$ is underestimated. The error analysis of the ice classes confirms that $T_{a}$ and $T_{s}$ uncertainties have the highest impact; $\mathrm{RH}$ and $U_{10 m}$ uncertainties have only a minimal impact on the retrieved ice thickness.

The results of the Monte Carlo error estimation for different ice classes and the winter seasons 2007/2008 and 2008/2009 are shown in Table VI. Comparing the uncertainty values for the two years, we find that, up to $20 \mathrm{~cm}$, the errors are low and almost the same (errors of 1 to $5 \mathrm{~cm}$ ). For thicker ice, the uncertainties become larger (errors of 12 to 
(a)

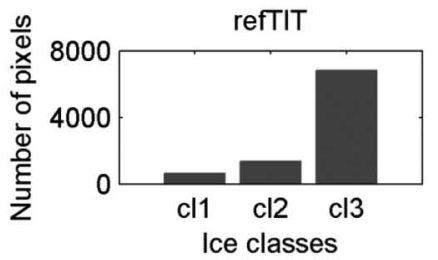

(b)

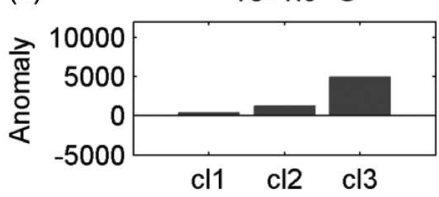

(d)

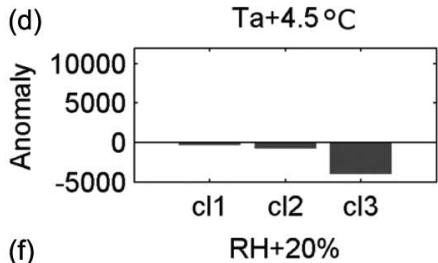

(f)

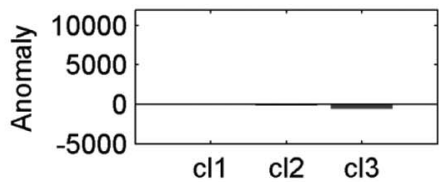

(h)

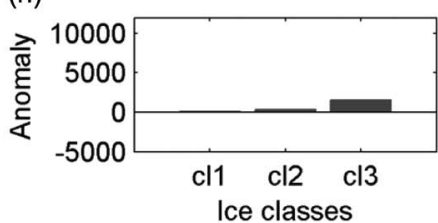

(c)

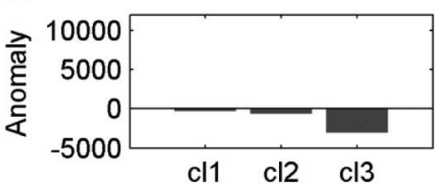

(e)

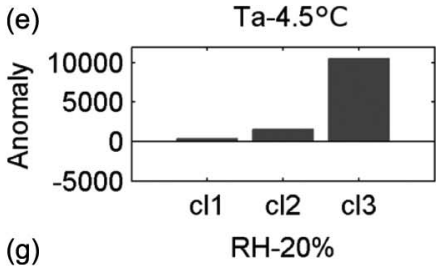

(g)
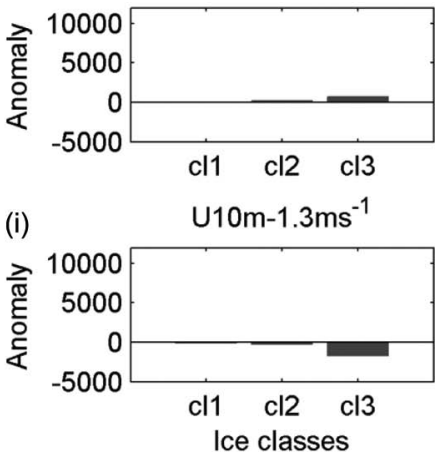

Fig. 4. (a) Averaged sum of reference thin-ice pixels for ice classes cl1 $(0-5 \mathrm{~cm}), \mathrm{cl} 2(5-10 \mathrm{~cm})$, and cl3 $(10-20 \mathrm{~cm})$. (b)-(i) Anomaly to reference ice thickness for the input variables with their minimum and maximum uncertainties (Table IV).

TABLE VI

Statistical Uncertainty Calculated With Monte Carlo ERror ESTIMATION USING THE UNCERTAINTIES LISTED IN TABLE IV FOR WiNTERS 2007/2008 AND 2008/2009 AND DIFFERENT ICE CLASSES

\begin{tabular}{c|r|r|r}
\hline & $\begin{array}{c}\text { Winter } \\
\mathbf{2 0 0 7 / 0 8}\end{array}$ & $\begin{array}{c}\text { Winter } \\
\mathbf{2 0 0 8 / 0 9}\end{array}$ & $\begin{array}{c}\text { Mean of both } \\
\text { winters }\end{array}$ \\
\hline Ice class (cm) & $\begin{array}{c}\text { TIT }_{\text {MODIS+NCEP }} \\
(\mathbf{c m})\end{array}$ & $\begin{array}{c}\text { TIT }_{\text {MODIS+NCEP }} \\
(\mathbf{c m})\end{array}$ & $\begin{array}{c}\text { TIT }_{\text {MODIS+NCEP }} \\
(\mathbf{c m})\end{array}$ \\
\hline $\mathbf{0 - \mathbf { 5 }}$ & \pm 1.0 & \pm 1.0 & \pm 1.0 \\
\hline $\mathbf{5 - 1 0}$ & \pm 2.0 & \pm 2.2 & \pm 2.1 \\
\hline $\mathbf{1 0} \mathbf{- 2 0}$ & \pm 5.2 & \pm 5.3 & \pm 5.3 \\
\hline $\mathbf{2 0} \mathbf{- 3 0}$ & \pm 16.8 & \pm 12.0 & \pm 14.4 \\
\hline $\mathbf{3 0} \mathbf{- 4 0}$ & \pm 34.2 & \pm 28.4 & \pm 31.3 \\
\hline $\mathbf{4 0} \mathbf{- 5 0}$ & \pm 36.7 & \pm 60.2 & \pm 48.5 \\
\hline \hline mean up to 20 & \pm 4.7 & \pm 4.6 & \pm 4.7 \\
\hline mean up to 50 & \pm 26.1 & \pm 36.0 & \pm 31.1 \\
\hline
\end{tabular}

$60 \mathrm{~cm})$ and differ strongly between the two winter seasons (24-cm difference for the ice class $40-50 \mathrm{~cm}$ ). Again, the uncertainties of the input variables have a higher impact on thicker ice. A further explanation about this feature is given in Section IV-B.

The mean uncertainties in the ice thicknesses from 0 to $20 \mathrm{~cm}$ are $\pm 4.7 \mathrm{~cm}$ for winter $2007 / 2008$ and $\pm 4.6 \mathrm{~cm}$ for winter 2008/2009, and the mean over both seasons is $\pm 4.7 \mathrm{~cm}$. For the ice thicknesses from 0 to $50 \mathrm{~cm}$, the mean uncertainties are $\pm 26.1 \mathrm{~cm}$ for winter $2007 / 2008$ and $\pm 36.0 \mathrm{~cm}$ for winter $2008 / 2009$, and the mean over both seasons is $\pm 31.1 \mathrm{~cm}$.

The results of the Monte Carlo error estimation lead to the conclusion that, for subsequent application, only MODIS ice thicknesses up to $20 \mathrm{~cm}$ should be used. In terms of ice production, ice thicknesses in this range are sufficient since we assume that ice formation rates are strongest in regions with ice thicknesses up to $20 \mathrm{~cm}$.

Summarizing the results of the statistical sensitivity analysis, we find the following.

1) The mean absolute errors for both winter seasons are $\pm 4.7 \mathrm{~cm}$ for ice of $0-20 \mathrm{~cm}$ thickness and $\pm 31.1 \mathrm{~cm}$ for ice of $0-50 \mathrm{~cm}$ thickness.

2) The uncertainty in $T_{s}$ and $T_{a}$ influence strongly the calculation of the ice thickness.

3) An underestimation of $T_{a}$ results in a strong underestimation of the ice thickness (i.e., more pixels with ice thicknesses below $20 \mathrm{~cm}$ and hence larger polynya areas); an overestimation of $T_{a}$ results in an overestimation of the ice thickness, but the anomaly to the reference value is moderate.

4) The uncertainties in the atmospheric variables have a smaller impact on very thin ice (up to $10 \mathrm{~cm}$ ) than on thicker ice.

5) For subsequent applications, MODIS ice thicknesses below $20 \mathrm{~cm}$ should only be used.

\section{B. Comparative Sensitivity Analysis}

The statistical analysis gives the uncertainty in the ice thickness in dependence of the mean uncertainties in the NCEP atmospheric variables. The comparative sensitivity analysis investigates the uncertainties which can emerge from different atmospheric data sets. As atmospheric data sets, we consider, on the one hand, NCEP data and, on the other hand, COSMO data with regional coverage of the Laptev Sea. The reasons for 
using COSMO additionally as an atmospheric data set are the following.

1) Reference [15] shows that COSMO data better agree with observations on the fast ice compared to NCEP.

2) Because of the high resolution, COSMO simulations include the impact of the polynyas on the atmospheric boundary layer.

Two selected case studies are analyzed and discussed in the following. We focus on the ice thicknesses up to $20 \mathrm{~cm}$ (see Section IV-A). Additionally, Envisat ASAR images are used for comparison.

The first case study was chosen for January 3, 2009, 0135 UTC (Fig. 5). The polynya is part of the Anabar-Lena polynya. It opens on December 30, 2008, and closes on January 7, 2009. MODIS $T_{s}$ resolves the polynya structure with a sharp temperature transition between fast ice and polynya area. Adjacent to the fast-ice edge, a small band of relatively high temperatures (around $-8{ }^{\circ} \mathrm{C}$ ) occurs, indicating an area of very thin ice. Going further offshore, the surface temperature decreases continuously. The NCEP $T_{a}$ field does not show a polynya signal (no heating of the lower atmosphere). Air temperatures are almost homogenously distributed $\left(T_{a}\right.$ around $\left.-22{ }^{\circ} \mathrm{C}\right)$ in the whole Laptev Sea. In contrast, the COSMO $T_{a}$ field shows higher temperatures (up to $-15{ }^{\circ} \mathrm{C}$ ) in polynya regions and an abrupt change to very cold temperatures (around $-22^{\circ} \mathrm{C}$ ) going further offshore. However, the COSMO $T_{a}$ pattern is not the same as that for MODIS $T_{s}$.

Contour lines for ice thicknesses of 10 and $20 \mathrm{~cm}$ are shown in Fig. 5(a) and (c). The total polynya area with thin ice $\leq 20$ $\mathrm{cm}$ is the same for the ice thickness products TIT $_{\text {MODIS }+ \text { NCEP }}$ and TIT $_{\text {MODIS+COSMO and consistent with the polynya area }}$ shown in Envisat ASAR backscatter coefficients [Fig. 5(e)].

In the following, the main problems resulting from the use of coarse resolution NCEP data in combination with MODIS $T_{s}$ are examined. In addition, the case study also shows how the high-resolution COSMO data interact on MODIS ice thicknesses. When interpreting TIT $_{\text {MODIS+COSMO, the differ- }}$ ences between polynya area from the remote sensing data sets MODIS and AMSR-E have to be taken into account.

The interdependence of $T_{s}$ and $T_{a}$ and the impact on the retrieved ice thickness are illustrated with the across-polynya transects shown in Fig. 5(f) and (g). Comparing the temperatures and the corresponding ice thicknesses, we can divide the transect into two domains. In domain I, consistent temperature peaks of COSMO $T_{a}$ and MODIS $T_{s}$ are observed starting at the transition region between fast ice and very thin ice. NCEP $T_{a}$ is constant over the entire transect and up to $4{ }^{\circ} \mathrm{C}$ lower than COSMO $T_{a}$. Despite the difference in NCEP and COSMO $T_{a}$, the resulting ice thickness starts with very thin ice for both

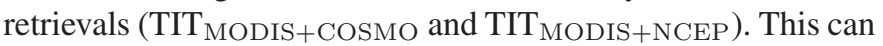
be explained with the strong temperature gradient between surface and lower atmosphere (term in the equation for the calculation of $H_{0}$ ) in regions of very thin ice, leading to similar ice thicknesses mostly independent of the atmospheric data sets. Due to these strong temperature differences, the uncertainties of the atmospheric input variables are masked. Since the quality of MODIS $T_{s}$ is high (accuracy of $\pm 1.6{ }^{\circ} \mathrm{C}$ ) and taking this masking effect into account, the thermal TITs are reliable up to $10 \mathrm{~cm}$, more or less independent of the uncertainties in the atmospheric variables for this case study. This is supported by the statistical sensitivity analysis (Fig. 4 and Table VI). With increasing distance to the fast-ice edge (end of domain I), the peak in COSMO $T_{a}$ leads to thicker ice in TIT $_{\text {MODIS+COSMO in }}$

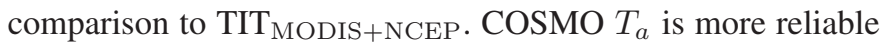
because the modification of the atmospheric boundary layer due to polynyas is taken into account, resulting in higher air temperatures. Hence, ice thickness retrievals are more reliable. NCEP $T_{a}$ is underestimated, resulting in underestimated ice thicknesses. This means that atmospheric data sets which do not capture polynyas generally underestimate $T_{a}$ in these regions as well as underestimate the calculated TIT.

In domain II, MODIS $T_{s}$ indicates a gradual thickening of

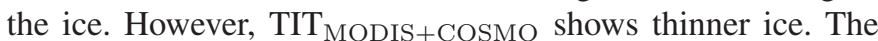
ice thickness for both TIT products is almost identical. This indicates that COSMO and NCEP $T_{a}$ are both too low. While the inconsistency between MODIS $T_{s}$ and NCEP $T_{a}$ is obvious (too coarse spatial resolution and no polynyas), the explanation for the COSMO data is given by inconsistencies between the AMSR-E-based polynya mask used in COSMO and MODIS data. The polynya signal in COSMO simulations results from AMSR-E SICs used as lower boundary and the model's fine spatial resolution $(5 \mathrm{~km})$ which is able to resolve polynyas. In the COSMO model, all grid cells with AMSR-E SIC below $70 \%$ are set to $10-\mathrm{cm}$ ice thickness; all other sea ice grid cells are set to $1-\mathrm{m}$ ice thickness. This jump from thin ice to thick ice results in the relatively abrupt temperature decrease of COSMO $T_{a}$ downstream the temperature peak [Fig. 5(d) and (f)]. In the following, the differences between polynya area derived from MODIS and AMSR-E is investigated in more detail. Although ice thicknesses are also derived from AMSR-E [21], these methods rely on a calibration using MODIS ice thicknesses. Thus, SIC from AMSR-E is used. In accordance with other studies, it is assumed that all grid cells with AMSR-E SIC below $70 \%$ describe the polynya area (e.g., [13] and [14]). In order to investigate the ability of AMSR-E to capture polynyas, Fig. 6

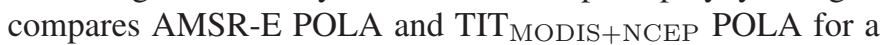
complete winter period. The results indicate that, in general, the AMSR-E POLA captures polynyas of an ice thickness between 10 and $15 \mathrm{~cm}$. Polynya regions including higher ice thickness are mostly missing, particularly for mid-winter months. In view of these results, it is reasonable that a mean ice thickness of $10 \mathrm{~cm}$ is used for polynya areas in COSMO. However, in regions with thicker ice not classified as a polynya, COSMO $T_{a}$ gives low temperatures as expected in drift ice regions. A transition zone of continuously decreasing temperatures as seen in MODIS $T_{s}$ also for thicker ice than $10-20 \mathrm{~cm}$ is therefore not represented in COSMO $T_{a}$, resulting in the temperature jump mentioned before.

The differences in the MODIS $T_{s}$ product and the AMSR-E data result from the different measurement techniques of both data sets. The MODIS data set has, with $1 \times 1 \mathrm{~km}^{2}$, a finer spatial resolution as the AMSR-E data $\left(6.25 \times 6.25 \mathrm{~km}^{2}\right)$. The coarse spatial resolution of AMSR-E data has an impact on the quality of the ice concentration retrieval. Pixels between fast/drift ice and open water/thin ice are influenced by both 
(a)

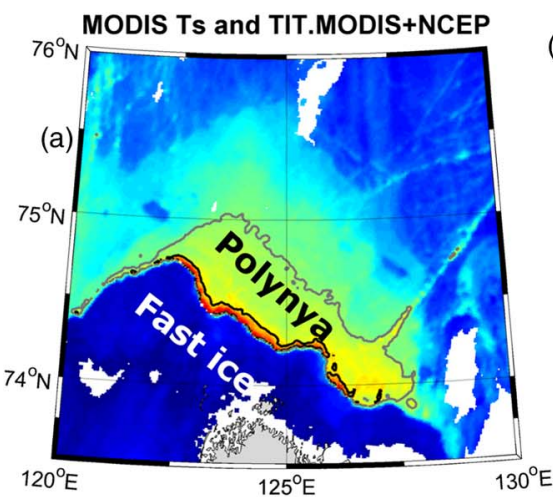

(b)
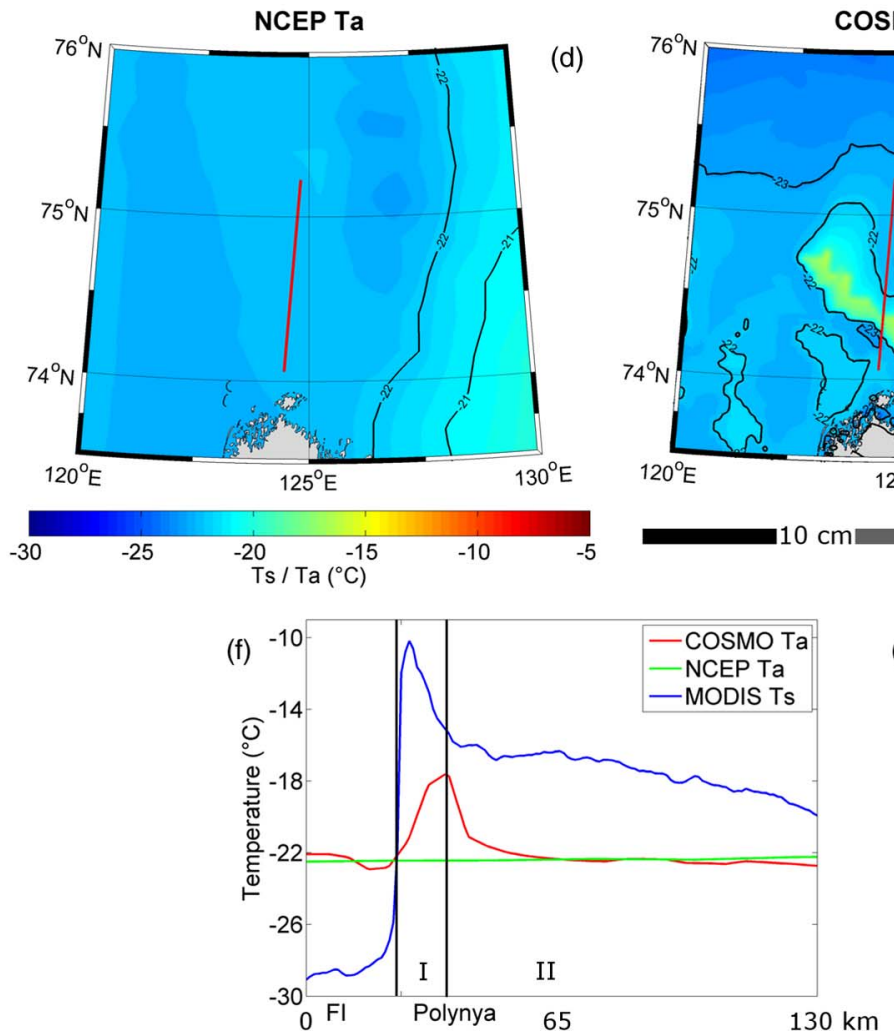

(c)

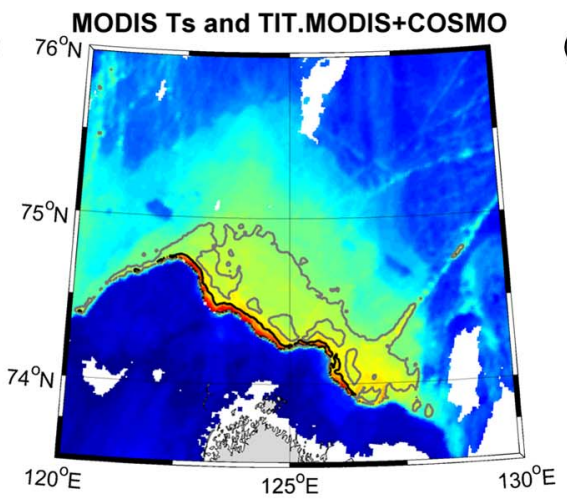

(d)

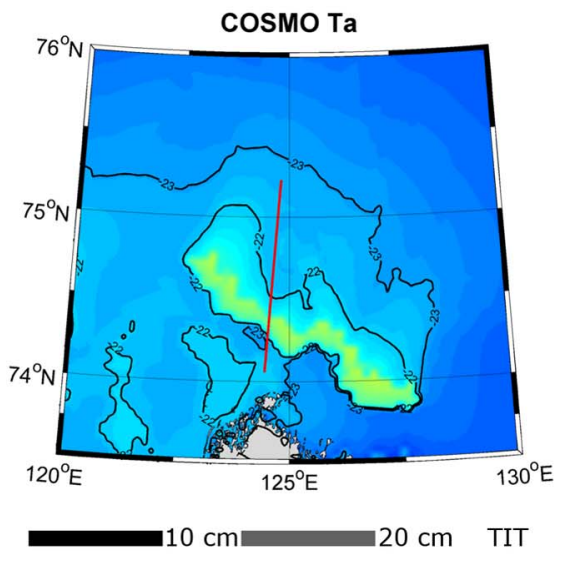

(e)

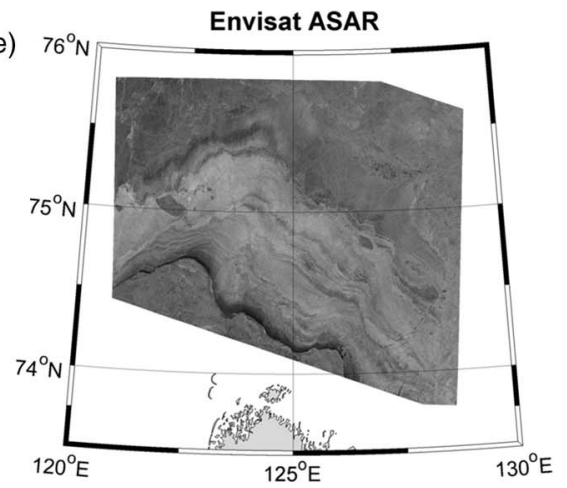

(g)

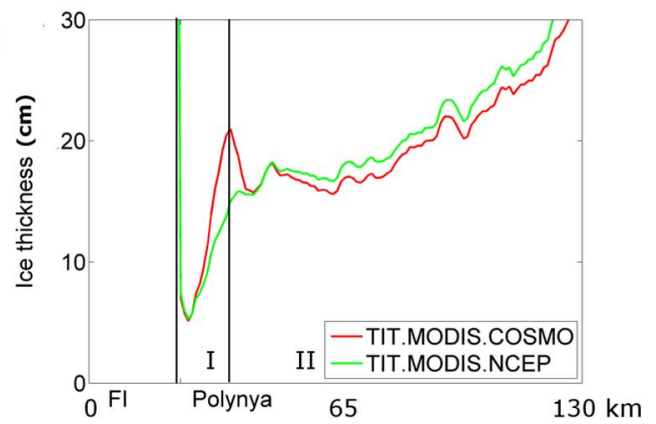

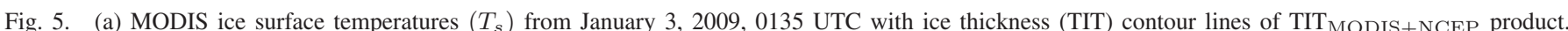
(b) Corresponding NCEP 2-m air temperature $\left(T_{a}\right)$ from January 3, 2009, 0000 UTC. (c) MODIS $T_{s}$ from the same date with ice thickness contour lines of

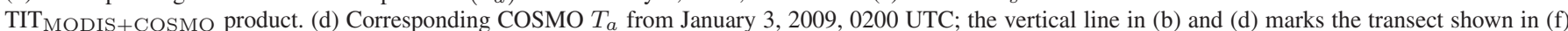
and (g). (e) Envisat ASAR image of January 3, 2009, 0243 UTC. (f) NCEP COMSO $T_{a}$ and MODIS $T_{s}$ for the transect across the polynya. (g) Ice thickness as

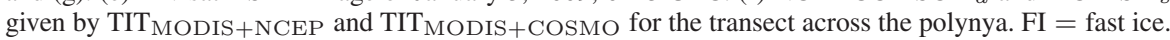

ice types, resulting in mixture pixels as stated by [19]. In particular, this is important for narrow polynyas. Due to these characteristics, AMSR-E POLA is generally underestimated in

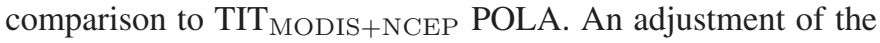
SIC threshold from $70 \%$ to a higher value does not yield better results but leads to misclassification in non-polynya regions. We conclude that COSMO data include flaw polynyas, but the size is underestimated.

The second case study shows an open polynya in the AnabarLena region on January 6, 2009, 0205 UTC (Fig. 7). MODIS $T_{s}$ is around $-5{ }^{\circ} \mathrm{C}$ adjacent to the fast-ice edge and decreases going further offshore. Again, NCEP $T_{a}$ is homogenously distributed (around $-15{ }^{\circ} \mathrm{C}$ ). COSMO gives $T_{a}$ around $-17^{\circ} \mathrm{C}$ in the polynya region and around $-23^{\circ} \mathrm{C}$ in the fast-ice and driftice regions and shows again the abrupt temperature decrease at the offshore polynya border. As mentioned for the first case study, the polynya seen in COSMO $T_{a}$ is here narrower than the polynya signal in MODIS $T_{s}$.

Although no polynya is captured in NCEP, $T_{a}$ is, in all regions (fast ice, polynya, and drift ice), warmer than COSMO $T_{a}$. In the polynya region, NCEP $T_{a}$ is around $2{ }^{\circ} \mathrm{C}$ warmer; in fast-ice and drift-ice regions, NCEP $T_{a}$ is around $8{ }^{\circ} \mathrm{C}$ warmer than COSMO $T_{a}$. The NCEP warm bias occurs in relation to COSMO for the two winter seasons 2007/2008 and $2008 / 2009$ with a mean bias of $1{ }^{\circ} \mathrm{C}$ and $3{ }^{\circ} \mathrm{C}$, respectively (not shown). If NCEP $T_{a}$ is overestimated, thin-ice retrievals with MODIS $T_{s}$ and NCEP atmospheric variables will result in overestimated ice thicknesses [Fig. 7(e)]. In contrast, the calculated ice thicknesses with MODIS $T_{s}$ and COSMO atmospheric variables are thinner for this case study [Fig. 7(f)]. The area 


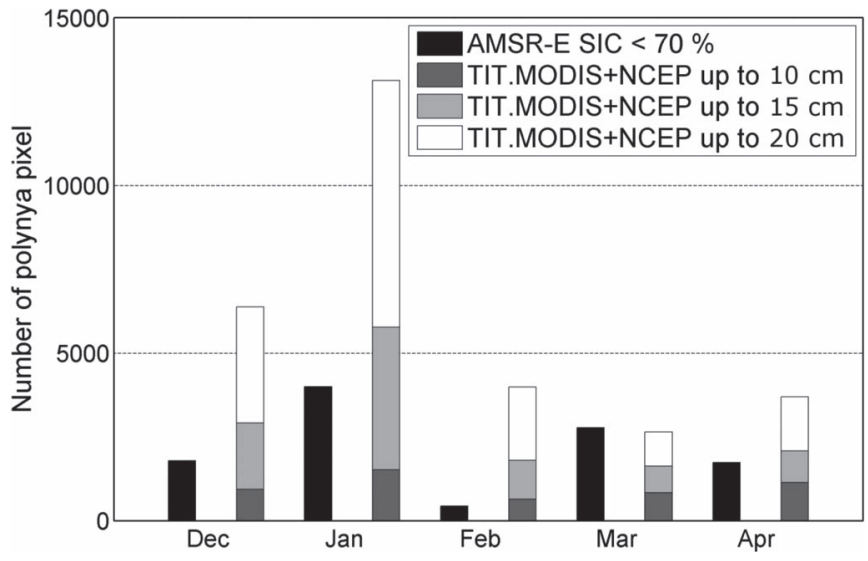

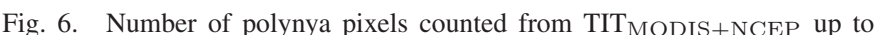
$10 \mathrm{~cm}$ (dark gray), $15 \mathrm{~cm}$ (light gray), and $20 \mathrm{~cm}$ (white) as well as the number of polynya pixels as counted from AMSR-E SICs lower than $70 \%$ (black) for December 2007 to April 2008. MODIS and AMSR-E are interpolated to the $5-\mathrm{km}$ COSMO grid.

with ice thicknesses less than 20 -cm ice thickness is extremely large for TIT $_{\text {MODIS+COSMO (large polynya) in comparison to }}$

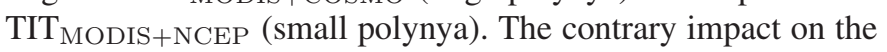
derived ice thicknesses using overestimated or underestimated $T_{a}$ is striking. In agreement with the statistical analysis (Fig. 4), the case study shows that an underestimation of $T_{a}$ has a strong influence on the retrieved ice thickness (ice thicknesses are extremely underestimated).

Taking this warm bias of NCEP $T_{a}$ into account, the difference of the errors for the two winters for thicker ice than $20 \mathrm{~cm}$ can be explained (Monte Carlo error estimation; Table VI). The difference results from errors in the NCEP data. The number of dates with underestimated or overestimated NCEP $T_{a}$ during polynya events must be different in the two years, resulting in different ice thickness errors. However, since we discovered the masking effect for very thin ice due to the strong temperature gradient between surface and lower atmosphere (see Section IV-B), the differences in uncertainties between the two winter seasons are first obvious for thicker ice.

The Envisat ASAR image for the same date shows a polynya signature. However, we cannot draw a conclusion about the thin-ice distribution from Envisat ASAR to decide which thermal ice thickness distribution is more reliable.

Summarizing the results from the two case studies, the following four situations concerning uncertainties of the atmospheric variables and their effect on the retrieved ice thickness can be identified.

1) COSMO has a polynya temperature signal which corresponds to the MODIS $T_{s}$ polynya signal (see case study of [19]): highest accuracy of the resulting thin-ice retrieval.

2) COSMO has a polynya signal, but the polynya is narrower than the one in MODIS data: high accuracy in the area where COSMO variables are adjusted to the polynya and too thin ice in the area where MODIS still shows a polynya signal and COSMO $T_{a}$ is too low (inconsistency at the $T_{a}$ jump from thin ice to thick ice).

3) COSMO (if the polynya is extremely narrow and not resolved in AMSR-E SIC) and NCEP do not show a polynya signal ( $T_{a}$ underestimated): retrieved ice thicknesses are too thin.

4) NCEP $T_{a}$ is overestimated (warm bias): retrieved ice thicknesses are too thick.

\section{Summary AND CONCLUSion}

Thermal TITs in the Laptev Sea polynya are retrieved for all available MODIS scenes in the winter seasons 2007/2008 and 2008/2009. The algorithm based on [31] was improved with respect to the calculation of the atmospheric flux components. This includes an iterative approach to calculate the turbulent heat fluxes (variable heat transfer coefficient $C_{H}$ ) based on [45] and an improved parameterization of the atmospheric emission coefficient $\varepsilon_{a}$ following [43].

The comparison of the transfer coefficient applied in [31] with the present results implies that the use of a constant $C_{H}$ as in [31] leads to an underestimation of the ice thickness. The parameterization of long-wave radiation according to [47] in comparison to [43] results in an overestimation of the retrieved ice thickness. The modified parameterizations are expected to result in improved ice thicknesses because the stratification of the atmospheric boundary layer is taken into account.

A statistical error estimation is performed with MODIS $T_{s}$ and NCEP atmospheric variables for the two winter seasons $2007 / 2008$ and 2008/2009. First, the ranking of all input variables is analyzed. It is found that the uncertainties of the $2-\mathrm{m}$ air temperature $T_{a}$ and the ice surface temperature $T_{s}$ have the highest impact on the derived TIT. Second, a Monte Carlo error estimation is performed for all MODIS scenes in the two winter seasons. The errors between both winters differ for ice thicker than $20 \mathrm{~cm}$, indicating the high influence of the uncertainty in NCEP $T_{a}$. The mean absolute error for ice thicknesses up to $20 \mathrm{~cm}$ is $\pm 4.7 \mathrm{~cm}$.

The comparative sensitivity analysis shows two case studies with NCEP and COSMO $T_{a}$ as well as the derived TIT pro-

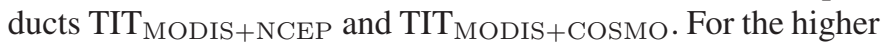
quality atmospheric data set COSMO, the results show that the prescription of the sea ice field using AMSR-E SIC gives too narrow polynyas in comparison to MODIS $T_{s}$. Due to these inconsistencies between MODIS and AMSR-E polynya areas, an underestimation of the ice thickness occurs with farther distance from the fast-ice edge. We conclude that at a simple prescription of the polynya area as done in the COSMO model configuration is not sufficient to simulate realistically the atmospheric variables. A prescription of the thin-ice distribution in atmospheric models as provided by our thin-ice product

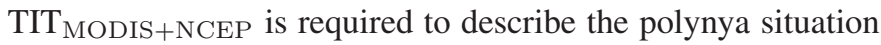
more accurate.

In contrast, NCEP atmospheric data do not capture polynyas but show a homogenously distributed $T_{a}$. If the NCEP $T_{a}$ is underestimated, the retrieved ice thickness is too thin. However, the temperature bias in NCEP $T_{a}$ found in comparison to COSMO $T_{a}$ leads to rather overestimated ice thicknesses.

The following can be demonstrated: 1) the uncertainties in very thin ice is mostly independent of the uncertainties in the atmospheric variables, and 2) an underestimation of $T_{a}$ results in a strong underestimation of the ice thickness, and an 
(a)

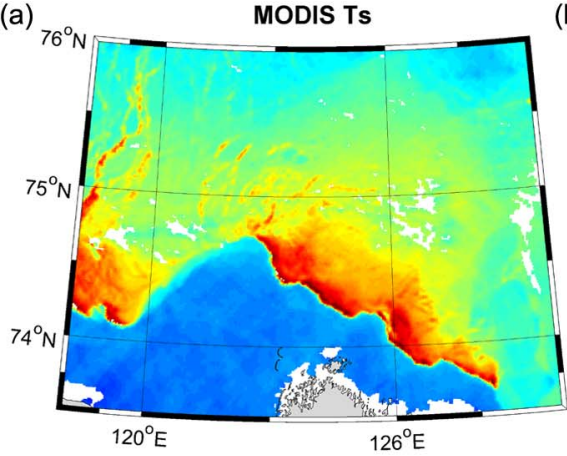

(d)

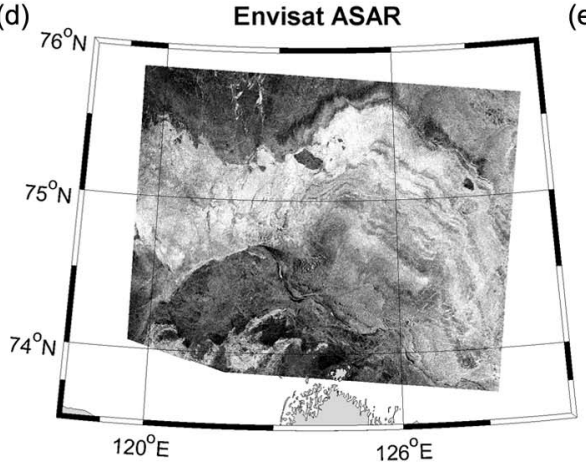

(b)

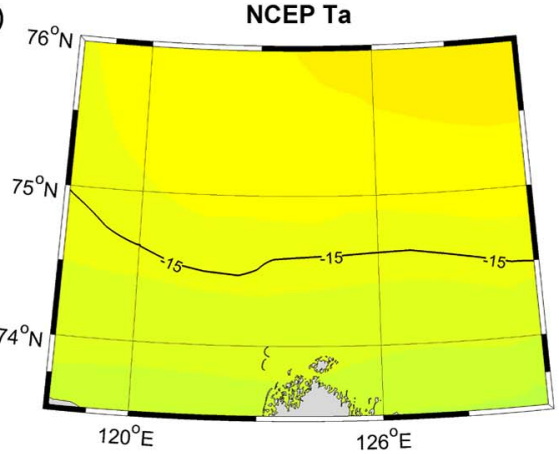

(e)

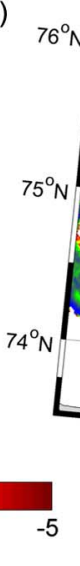

TIT.MODIS+NCEP

0 (c)

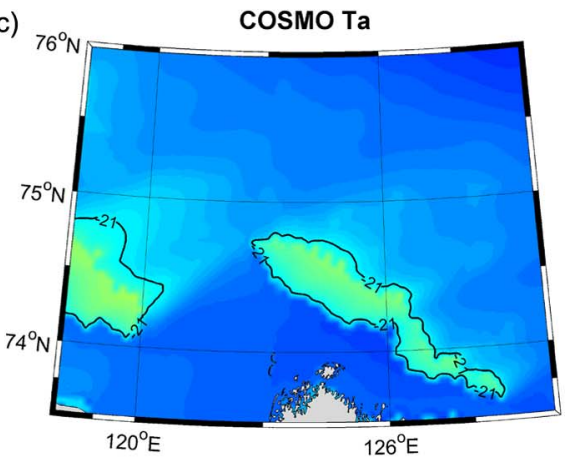

(f)

TIT.MODIS+COSMO

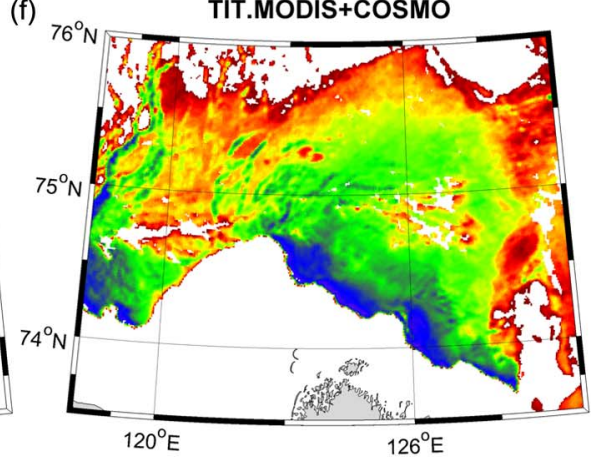

Fig. 7. (a) MODIS ice surface temperatures $\left(T_{s}\right)$ from January 6, 2009, 0205 UTC. (b) Corresponding NCEP 2-m air temperature $\left(T_{a}\right)$ from January 6, 2009, 0000 UTC. (c) Corresponding COSMO $T_{a}$ from January 6, 2009, 0200 UTC. (d) Envisat ASAR image of January 6, 2009,0248 UTC. (e) Ice thickness distribution as calculated with MODIS $T_{s}$ and NCEP atmospheric variables (TIT $\mathrm{MODIS+NCEP}$ ). (f) Ice thickness distribution as calculated with MODIS $T_{s}$ and COSMO atmospheric variables ( TIT $_{\text {MODIS }+ \text { COSMO). }}$.

overestimation of $T_{a}$ results only in a moderate overestimation of the ice thickness. Therefore, it can be concluded that the NCEP data set is appropriate for the calculation of the TITs up to $20 \mathrm{~cm}$ in the Laptev Sea for the two winter seasons 2007/2008 and 2008/2009. Moreover, the combination of MODIS $T_{s}$ with NCEP atmospheric variables is applicable for the calculation of TIT up to $20 \mathrm{~cm}$ for longer time periods (2000-today) and other polar regions. When applying the energy balance model to longer periods, problems with the MODIS cloud mask could appear. During the night, MODIS visible channels cannot be used to identify clouds, reducing the quality of the mask. Our thin-ice studies are therefore only focused on sea ice regions where polynyas occur (for the application of a polynya mask, see previous discussion). This helps in reducing thin-ice artifacts.

TIT $_{\text {MODIS+NCEP for the two winters represents a valuable }}$ high-resolution verification data set for sea ice simulations and remote sensing methods. However, a complete spatial coverage of sea ice areas is rare because of the limitations by cloud coverage and nighttime conditions. This problem is partly solved by building daily composites (similar to [50] and [51]), which results in about $70 \%$ data coverage for the two winters.

A future perspective in terms of the improvement of the TIT algorithm could be a closer coupling with atmospheric model data. For example, the radiation fluxes from the COSMO model could be used instead of simple empirical parameterizations.

Referring to the atmospheric data sets, the ERA-Interim data set will be additionally used in combination with MODIS to calculate the TIT in future studies. The ERA model captures polynyas using SSM/I data. However, preliminary results also show a warm bias for ERA-Interim data because the areas with increased temperatures above the polynyas are too large. Further examination is necessary here.

With regard to the shortcomings of the 2-m air temperature from atmospheric models, a bias correction is under development in order to adjust NCEP and COSMO $T_{a}$, respectively. This correction of the model air temperature could increase the quality of the MODIS TIT data set.

\section{ACKNOWLEDGMENT}

The COSMO model was made available by the German Weather Service. MODIS ice surface temperatures (MOD29/ MYD29) are provided by the US National Aeronautics and Space Administration. NCEP/DOE Reanalysis II data are obtained from the Earth System Research Laboratory, US National Oceanic and Atmospheric Administration. AMSR-E sea ice concentrations are provided by the University of Hamburg.

\section{REFERENCES}

[1] J. C. Stroeve, M. C. Serreze, M. M. Holland, J. E. Kay, J. Malanik, and A. P. Barrett, "The Arctic's rapidly shrinking sea ice cover: A research synthesis," Clim. Change, vol. 110, no. 3/4, pp. 1005-1027, Feb. 2012.

[2] R. Kwok and N. Untersteiner, "The thinning of Arctic sea ice," Phys. Today, vol. 64, no. 4, pp. 1-36, Apr. 2011.

[3] S. Willmes, S. Adams, D. Schröder, and G. Heinemann, "Spatio-temporal variability of polynya dynamics and ice production in the Laptev Sea 
between the winters of 1979/80 and 2007/08," Polar Res., vol. 30, p. 5971, May 2011.

[4] T. Tamura and K. I. Oshima, "Mapping of sea ice production in the Arctic coastal polynyas," J. Geophys. Res, vol. 116, pp. C07 030-1-C07 030-20, Jul. 2011.

[5] L. Ebner, D. Schröder, and G. Heinemann, "Impact of the Laptev Sea flaw polynyas on the atmospheric boundary layer and ice production using idealized mesoscale simulations," Polar Res., vol. 30, p. 7210, May 2011.

[6] D. Dethleff, P. Loewe, and E. Kleine, "The Laptev Sea flaw lead-Detailed investigation on ice formation and export during 1991/1992 winter season," Cold Reg. Sci. Technol., vol. 27, no. 3, pp. 225243, Jun. 1998.

[7] P. Winsor and G. Björk, "Polynya activity in the Arctic Ocean from 1958 to 1997," J. Geophys. Res, vol. 105, no. C4, pp. 8789-8803, Apr. 2000.

[8] I. A. Dmitrenko, S. A. Kirillov, L. B. Tremblay, D. Bauch, and S. Willmes, "Sea-ice production over the Laptev Sea shelf inferred from historical summer-to-winter hydrographic observations of 1960s-1990s," Geophys. Res. Lett., vol. 36, pp. L13 605-1-L13 605-4, Jul. 2009.

[9] S. Kern, L. Kaleschke, and D. A. Clausi, "A comparison of two 85-GHz SSM/I ice concentration algorithms with AVHRR and ERS-2 SAR imagery," IEEE Trans. Geosci. Remote Sens., vol. 41, no. 10, pp. 2294-2306, Oct. 2003

[10] S. Andersen, R. Tonboe, L. Kaleschke, G. Heygster, and L. T. Pedersen, "Intercomparison of passive microwave sea ice concentration retrievals over the high-concentration Arctic sea ice," J. Geophys. Res, vol. 112, pp. C08 004-1-C08 004-18, Aug. 2007.

[11] L. Kaleschke, C. Lüpkes, T. Vihma, J. Haarpaintner, A. Bochert, J. Hartmann, and G. Heygster, "SSM/I sea ice remote sensing for mesoscale ocean-atmosphere interaction analysis," Can. J. Remote Sens, vol. 27 , no. 5 , pp. 526-537, 2001.

[12] G. Spreen, L. Kaleschke, and G. Heygster, "Sea ice remote sensing using AMSR-E 89-GHz channels," J. Geophys. Res, vol. 113, pp. C02S03-1C02S03-14, Jan. 2008.

[13] R. A. Massom, P. T. Harris, K. J. Michael, and M. J. Potter, "The distribution and formative processes of latent-heat polynyas in East Antarctica," Ann. Glaciol, vol. 27, pp. 420-426, 1998.

[14] S. Adams, S. Willmes, G. Heinemann, P. Rozman, R. Timmermann, and D. Schröder, "Evaluation of simulated sea-ice concentrations from seaice/ocean models using satellite data and polynya classification methods," Polar Res., vol. 30, p. 7124, May 2011.

[15] T. Ernsdorf, D. Schröder, S. Adams, G. Heinemann, R. Timmermann, and S. Danilov, "Impact of atmospheric forcing data on simulations of the Laptev Sea polynya dynamics using the sea-ice ocean model FESOM," $J$. Geophys. Res., vol. 116, pp. C12 038-1-C12 038-18, Dec. 2011.

[16] T. Markus and B. A. Burns, "A method to estimate subpixel-scale coastal polynyas with satellite passive microwave data," J. Geophys. Res., vol. 100, no. C3, pp. 4473-4487, 1995.

[17] S. Kern, G. Spreen, L. Kaleschke, S. De la Rosa, and G. Heygster, "Polynya Signature Simulation Method polynya area in comparison to AMSR-E $89 \mathrm{GHz}$ sea-ice concentrations in the Ross Sea and off the Adélie Coast, Antarctica, for 2002-05: First results," Ann. Glaciol., vol. 46, no. 1, pp. 409-418, Oct. 2007.

[18] S. Kern, "Wintertime Antarctic coastal polynya area: 1992-2008," Geophys. Res. Lett, vol. 36, pp. L14 501-L14 501-5, Jul. 2009.

[19] S. Willmes, T. Krumpen, S. Adams, L. Rabenstein, C. Haas, J. Hölemann, S. Hendricks, and G. Heinemann, "Cross-validation of polynya monitoring methods from multisensor satellite and airborne data: A case study for the Laptev Sea," Can. J. Remote Sens., vol. 36, no. S1, pp. S196-S210, Jan. 2010.

[20] S. Martin, "Estimation of the thin ice thickness and heat flux for the Chukchi Sea Alaskan coast polynya from Special Sensor Microwave/Imager data, 1990-2001," J. Geophys. Res., vol. 109, pp. C10 012-1-C10 012-15, Oct. 2004.

[21] S. Martin, "Improvements in the estimates of ice thickness and production in the Chukchi Sea polynyas derived from AMSR-E," Geophys. Res. Lett., vol. 32, pp. L05 505-1-L05 505-4, Mar. 2005.

[22] T. Tamura, K. I. Ohshima, T. Markus, D. J. Cavalieri, S. Nihashi, and N. Hirasawa, "Estimation of thin ice thickness and detection of fast ice from SSM/I data in the Antarctic ocean," J. Atmos. Ocean. Technol., vol. 24 , no. 10 , pp. $1757-1772$, Oct. 2007.

[23] R. K. Singh, S. R. Oza, N. K. Vyas, and A. Sarkar, "Estimation of thin ice thickness from the advanced microwave scanning radiometer-EOS for coastal polynyas in the Chukchi and Beaufort Seas," IEEE Trans. Geosci. Remote Sens., vol. 49, no. 8, pp. 2993-2998, Aug. 2011.

[24] P. M. Kuhn, L. P. Sterns, and R. O. Ramseier, "Airborne infrared imagery of arctic sea ice thickness," U.S. Dept. Commerce, NOAA, Environmental Res. Lab., Boulder, CO, Tech. Rep. ERL 331-APCL 34, 1975.
[25] J. E. Groves and W. J. Stringer, "The use of AVHRR thermal infrared imagery to determine sea ice thickness within the Chukchi polynya," Arctic, vol. 44, no. 5, pp. 130-139, 1991.

[26] G. A. Maykut, "The surface heat and mass balance," in Geophysics of Sea Ice. NATO Advanced Science Institutes Series B, Physics, N. Untersteiner, Ed. New York: Plenum, 1986, pp. 395-463.

[27] Y. Yu and D. A. Rothrock, "Thin ice thickness from satellite thermal imagery," J. Geophys. Res., vol. 101, no. C11, pp. 25753-25766, Nov. 1996.

[28] G. A. Maykut and N. Untersteiner, "Some results from a time-dependent thermodynamic model of sea ice," J. Geophys. Res., vol. 76, no. 6, pp. $1550-1575,1971$.

[29] Y. Yu, D. A. Rothrock, and J. Zhang, "Thin ice impacts on surface salt flux and ice strength: Inferences from advanced very high resolution radiometer," J. Geophys. Res., vol. 106, no. C7, pp. 13975-13988, Jul. 2001.

[30] R. Drucker and S. Martin, "Observations of ice thickness and frazil ice in the St. Lawrence Island polynya from satellite imagery, upward looking sonar, and salinity/temperature moorings," J. Geophys. Res, vol. 108, no. C5, p. 3149, May 2003.

[31] Y. Yu and R. W. Lindsay, "Comparison of thin ice thickness distributions derived from RADARSAT Geophysical Processor System and advanced very high resolution radiometer data sets," J. Geophys. Res, vol. 108, no. C12, p. 3387, Dec. 2003.

[32] X. Wang, J. R. Key, and Y. Liu, "A thermodynamic model for estimating sea and lake ice thickness with optical satellite data," J. Geophys. Res, vol. 115, pp. C12 035-C12 035-14, Dec. 2010.

[33] D. K. Hall, G. A. Riggs, and V. V. Salomonson, MODIS/Terra and MODIS/Aqua Sea Ice Extent 5-min L2 Swath $1 \mathrm{~km}$ V005, 1st December 2007 till 30th April 2008 and 1st December 2008 till 30th April 2009. Boulder, CO: National Snow and Ice Data Center. Digital media, 2007, updated daily.

[34] D. K. Hall, J. R. Key, K. A. Case, G. A. Riggs, and D. J. Cavalieri, "Sea ice surface temperature product from MODIS," IEEE Trans. Geosci. Remote Sens., vol. 42, no. 5, pp. 1076-1087, May 2004.

[35] S. A. Ackerman, K. I. Strabala, W. P. Menzel, R. A. Frey, C. C. Moeller, and L. E. Gumley, "Discriminating clear sky from clouds with MODIS," J. Geophys. Res., vol. 103, no. D24, pp. 32 141-32 157, Dec. 1998.

[36] S. Platnick, M. King, S. Ackerman, W. Menzel, B. Baum, J. Riedi, and R. Frey, "The MODIS cloud products: Algorithms and examples from Terra," IEEE Trans. Geosci. Remote Sens., vol. 41, no. 2, pp. 459-473, Feb. 2003.

[37] J. Bareiss and K. Görgen, "Spatial and temporal variability of sea ice in the Laptev Sea: Analyses and review of satellite passive-microwave data and model results, 1979 to 2002," Global Planet Change, vol. 48, no. 1-3, pp. 28-54, Sep. 2005.

[38] X. Xiong, K. Stamnes, and D. Lubin, "Surface albedo over the Arctic Ocean derived from AVHRR and its validation with SHEBA data," $J$. Appl. Meteor. Climatol., vol. 41, no. 4, pp. 413-425, Apr. 2002.

[39] D. Schröder, G. Heinemann, and S. Willmes, "Implementation of a thermodynamic sea ice module in the NWP model COSMO and its impact on simulations for the Laptev Sea area in the Siberian Arctic," Polar Res, vol. 30, p. 5974, May 2011.

[40] M. Kanamitsu, W. Ebisuzaki, J. Woollen, S.-K. Yang, J. J. Hnilo, M. Fiorino, and G. L. Potter, "NCEP-DOE AMIP-II Reanalysis (R-2)," Bull. Amer. Meteor. Soc, vol. 83, no. 11, pp. 1631-1643, Nov. 2002.

[41] J. Steppeler, G. Doms, U. Schättler, H. W. Bitzer, A. Cassmann, U. Damrath, and G. Gregoric, "Meso-gamma scale forecasts using the nonhydrostatic model LM," Meteorol. Atmos. Phys., vol. 82, no. 1-4, pp. 75-96, 2003.

[42] U. Schättler, G. Doms, and C. Schraff, "A description of the nonhydrostatic regional COSMO-Model, Part VII," in User's Guide. Offenbach, Germany: Deutscher Wetterdienst, 2009, pp. 1-147.

[43] X. Jin, D. Barber, and T. Papakyriakou, "A new clear-sky downward longwave radiative flux parameterization for Arctic areas based on rawinsonde data," J. Geophys. Res., vol. 111, pp. D24 104-1-D24 104-7, Dec. 2006.

[44] W. G. Rees, "Infrared emissivities of Arctic land cover types," Int. J. Remote Sens., vol. 14, no. 5, pp. 1013-1017, 1993.

[45] J. Launiainen and T. Vihma, "Derivation of turbulent surface fluxes-An iterative flux-profile method allowing arbitrary observing heights," Environ. Softw., vol. 5, no. 3, pp. 113-124, Sep. 1990.

[46] D. B. Fissel and C. L. Tang, "Response of sea ice drift to wind forcing on the northeastern Newfoundland shelf," J. Geophys. Res., vol. 96, no. C10, pp. 18397-18 409, 1991.

[47] N. A. Efimova, "On methods of calculating monthly values of net long wave radiation," Meteorologiya i Gidrologiya, vol. 10, pp. 28-33, 1961. 
[48] W. Brutsaert, "On a derivable formula for long-wave radiation from clear skies," Water Resour. Res., vol. 11, no. 5, pp. 742-744, 1975.

[49] I. A. Renfrew, G. W. K. Moore, P. S. Guest, and K. Bumke, "A comparison of surface layer and surface turbulent flux observations over the Labrador Sea with ECMWF Analyses and NCEP Reanalyses," J. Phys. Oceanogr., vol. 32, no. 2, pp. 383-400, Feb. 2002.

[50] C. Drüe and G. Heinemann, "High-resolution maps of the sea-ice concentration from MODIS satellite data," Geophys. Res. Lett, vol. 31, pp. L20 403-1-L20 403-5, Oct. 2004.

[51] A. D. Fraser, R. A. Massom, and K. J. Michael, "A method for compositing polar MODIS satellite images to remove cloud cover for landfast sea-ice detection," IEEE Trans. Geosci. Remote Sens., vol. 47, no. 9, pp. 3272-3282, Sep. 2009.

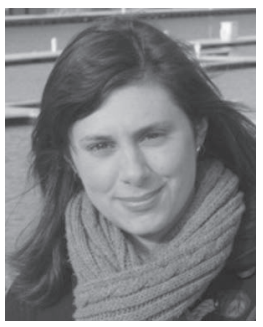

Susanne Adams received the diploma in applied environmental sciences from the University of Trier, Trier, Germany, in 2008. The topic of the diploma thesis was "the benefit of limb cloud imaging for tropospheric infrared limb sounding." She is currently working toward the Ph.D. degree in geosciences from the University of Trier.

She works as a scientific investigator in the field of polar climate. Her research is focused on the development of methods to investigate ice surface characteristics from remote sensing data in the Arctic

and Antarctic.

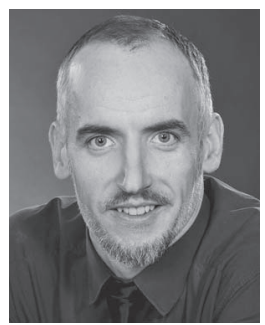

Sascha Willmes received the diploma in environmental sciences (with a focus on environmental data analysis and modeling) and the Ph.D. degree (based on his work on snow melt variability on Antarctic sea ice) from the University of Trier, Trier, Germany, in 2003 and 2007, respectively. The topic of the Ph.D. thesis was "Characterization of melt onset over Antarctic sea ice using remote sensing and in situ data."

He participated in several expeditions to the Arctic and Antarctic where he performed measurements of sea ice and snow properties in conjunction with remote sensing studies.

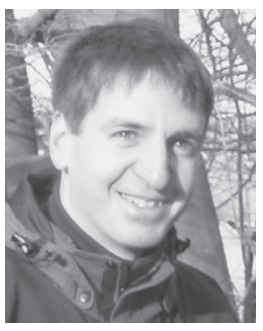

David Schröder received the Ph.D. degree in atmospheric sciences from the University of Hamburg, Hamburg, Germany, in 2005.

He was with the Polar Research group, University of Hamburg, from 1999 to 2006. He was a Research Associate with the British Antarctic Survey, Cambridge, U.K., from 2006 to 2007, studying the impact of sea ice initial conditions on climate simulations with the Hadley Centre Climate Model (HadCM3). From 2007 to 2010, he was a Lecturer and Researcher in Environmental Meteorology with the University of Trier, Trier, Germany. Since 2011, he has been a Manager and Developer of the sea ice model CICE at the Centre for Polar Observation and Modelling, University College London, London, U.K. His main research interests include sea ice physics, regional sea ice and atmospheric modeling, polynyas, and boundary layer meteorology.

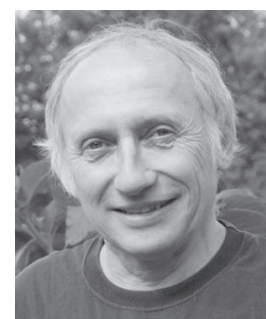

Günther Heinemann received the Ph.D. degree in meteorology from the University of Bonn, Bonn, Germany, in 1987.

From 1987 to 2005, he was a Research Scientist and Lecturer with the Meteorological Institute Bonn, Bonn, Germany and with the Institute for Geophysics and Meteorology, University of Cologne, Cologne, Germany. The research included atmospheric boundary layer studies, mesoscale modeling, and satellite remote sensing in mid-latitudes and polar regions. Since 2006, he has been a University Professor and the Head of the Department of Environmental Meteorology, University of Trier, Trier, Germany. His current research includes remote sensing of sea ice and atmosphere-ocean-sea-ice interaction using high-resolution regional models and experiments in the Arctic and Antarctic.

Dr. Heinemann has been the Chair of the German National SCAR/IASC Committee since 2010.

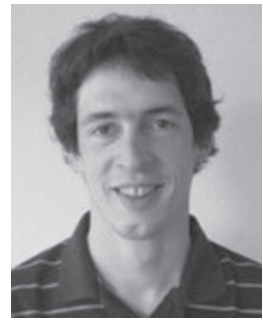

Martin Bauer received the diploma in applied environmental sciences from the University of Trier, Trier, Germany, in 2010, where he is currently working toward the Ph.D. degree in geosciences.

He works as a scientific investigator in the field of polar climate. His research is focused on sea ice and atmospheric modeling.

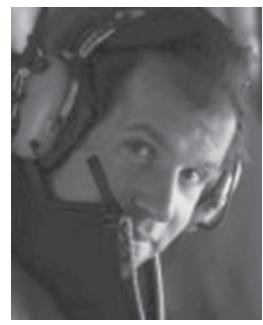

Thomas Krumpen received the Ph.D. degree in geoscience from the Jacobs University, Bremen, Germany, in 2010.

Since 2007, he has been with the Sea Ice Physics Department, Alfred Wegener Institute for Polar and Marine Research, Bremerhaven, Germany. His main research focus is on remote sensing of sea ice with a special emphasis on in situ ice thickness measurements using airborne electromagnetic induction. $\mathrm{He}$ is currently involved in several field campaigns with the objective of validating remote sensing products 